\title{
Interdependent Conductances Drive Infraslow Intrinsic Rhythmogenesis in a Subset of Accessory Olfactory Bulb Projection Neurons
}

\author{
Monika Gorin, ${ }^{1 \star}$ Chryssanthi Tsitoura, ${ }^{1 \star}$ Anat Kahan, ${ }^{3}$ Katja Watznauer, ${ }^{1}$ Daniela R. Drose, ${ }^{1}$ Martijn Arts, ${ }^{2}$ \\ Rudolf Mathar, ${ }^{2}$ Simon 0'Connor, ${ }^{4}$ Ileana L. Hanganu-0patz, ${ }^{5}$ Yoram Ben-Shaul, ${ }^{3}$ and ${ }^{\circledR}$ Marc Spehr ${ }^{1}$ \\ ${ }^{1}$ Department of Chemosensation, Institute for Biology II, ${ }^{2}$ Institute for Theoretical Information Technology, RWTH Aachen University, D-52074 Aachen, \\ Germany, ${ }^{3}$ School of Medicine, Department of Medical Neurobiology, The Hebrew University of Jerusalem, Jerusalem, 91120 Israel, ${ }^{4}$ Biocomputation \\ Group, University of Hertfordshire, Hatfield, Hertfordshire AL10 9AB, United Kingdom, and ${ }^{5}$ Developmental Neurophysiology, Institute of Neuroanatomy, \\ University Medical Center Hamburg-Eppendorf, D-20251 Hamburg, Germany
}

The accessory olfactory system controls social and sexual behavior. However, key aspects of sensory signaling along the accessory olfactory pathway remain largely unknown. Here, we investigate patterns of spontaneous neuronal activity in mouse accessory olfactory bulb mitral cells, the direct neural link between vomeronasal sensory input and limbic output. Both in vitro and in vivo, we identify a subpopulation of mitral cells that exhibit slow stereotypical rhythmic discharge. In intrinsically rhythmogenic neurons, these periodic activity patterns are maintained in absence of fast synaptic drive. The physiological mechanism underlying mitral cell autorhythmicity involves cyclic activation of three interdependent ionic conductances: subthreshold persistent $\mathrm{Na}^{+}$current, $\mathrm{R}$-type $\mathrm{Ca}^{2+}$ current, and $\mathrm{Ca}^{2+}$-activated big conductance $\mathrm{K}^{+}$current. Together, the interplay of these distinct conductances triggers infraslow intrinsic oscillations with remarkable periodicity, a default output state likely to affect sensory processing in limbic circuits.

Key words: intrinsic oscillations; mitral cell; olfactory bulb; pacemaker; rhythmogenesis; vomeronasal system

Significance Statement

We show for the first time that some rodent accessory olfactory bulb mitral cells-the direct link between vomeronasal sensory input and limbic output—are intrinsically rhythmogenic. Driven by $\geq 3$ distinct interdependent ionic conductances, infraslow intrinsic oscillations show remarkable periodicity both in vitro and in vivo. As a novel default state, infraslow autorhythmicity is likely to affect limbic processing of pheromonal information.

\section{Introduction}

In rodents, the accessory olfactory system controls conspecific chemical communication during social interactions. Behavior-

\footnotetext{
Received July 2, 2015; revised Dec. 22, 2015; accepted Jan. 11, 2016.

Author contributions: M.G., R.M., S.O., I.L.H.-O., Y.B.-S., and M.S. designed research;M.G., C.T., A.K., K.W., D.R.D., M.A., and S.O. performed research; M.G., C.T., A.K., K.W., R.M., I.L.H.-O., Y.B.-S., and M.S. analyzed data; M.G., S.O., I.L.H.-O., Y.B.-S., and M.S. wrote the paper.

This work was supported by grants from the Volkswagen Foundation (I/83533; to M.S.), the Deutsche Forschungsgemeinschaft (SP724/8-1, to M.S.; MA1184/20-2, to R.M.), DFG priority program SPP 1392: Integrative Analysis of Olfaction, Marie Skłodowska-Curie Actions (PCIG10-GA-2011-303785, to Y.B.-S.), the Lady Davis Fellowship Trust (to A.K.), and the German-Israeli Foundation for Scientific Research and Development (1-1193-153.13/ 2012, to M.S. and Y.B.-S.). M.S. is a Lichtenberg Professor of the Volkswagen Foundation. We thank both Corinna H. Engelhardt and Susanne Lipartowski (RWTH Aachen University) for excellent technical assistance.

${ }^{*} M$.G. and C.T. contributed equally to this work.

The authors declare no competing financial interests.

Correspondence should be addressed to Marc Spehr, RWTH Aachen University, Institute for Biology II/Dept. Chemosensation, Worringerweg 3, D-52074 Aachen, Germany. E-mail: m.spehr@sensorik.rwth-aachen.de.

DOI:10.1523/JNEUROSCI.2520-15.2016

Copyright $\odot 2016$ the authors $\quad 0270-6474 / 16 / 363127-18 \$ 15.00 / 0$
}

ally relevant chemosignals are detected by neurons in the vomeronasal organ and processed along sensory pathways that include the accessory olfactory bulb (AOB), amygdala, and hypothalamus (Stowers and Logan, 2010). While two of these three primary processing centers have been intensely studied (LeDoux, 2000; Simerly, 2002), central aspects of AOB physiology remain largely unexplored and functional analogies with neurons of the main olfactory bulb (MOB) are mostly speculative (Dulac and Wagner, 2006). Principal neurons, conventionally referred to as mitral cells, are the sole projection neurons of the AOB. These neurons extend complex, branched primary dendrites that receive excitatory synaptic input from vomeronasal sensory neurons in multiple glomeruli (Larriva-Sahd, 2008). This morphology indicates that sensory computation in $\mathrm{AOB}$ mitral cells is fundamentally different from the processing of "glomerulus-specific" information by their MOB counterparts (Dulac and Torello, 2003). Despite important recent insights into the organizational principles of connectivity, sensory input, and integration in the AOB (Del 
Punta et al., 2002; Ma and Lowe, 2004; Sugai et al., 2005; Wagner et al., 2006; Castro et al., 2007; Ben-Shaul et al., 2010; Smith and Araneda, 2010; Hovis et al., 2012; Leszkowicz et al., 2012; Shpak et al., 2012; Tolokh et al., 2013; Hammen et al., 2014), a conceptual understanding of how the biophysical properties of $\mathrm{AOB}$ mitral cells affect their computations is lacking.

Spontaneous activity is a major determinant of a neuron's coding capacity and information transfer function (Rieke et al., 1997). Spontaneous discharge may be sparse or dense, irregular or periodic, generating a continuum of neuronal firing patterns from Poisson-like discharge (Shadlen and Newsome, 1998) to rhythmic clock-like firing (Blankenship and Feller, 2010). Patterned discharge, such as burst firing and/or oscillatory activity, is particularly relevant for neural processing: bursts often represent units of information (Izhikevich et al., 2003), whereas oscillations provide precise temporal windows of excitability for circuit computations (Mizuseki et al., 2009). Different frequencies have been reported to encode specific brain states (Buzsáki et al., 2013). At the lower end of the time scale, oscillations extend into the slow $(0.1-1 \mathrm{~Hz})$ and infraslow $(<0.1 \mathrm{~Hz})$ range (Schroeder and Lakatos, 2009). Slow stereotypical episodic "up" and "down" states (Blethyn et al., 2006) could either result from regular recurrence of excitatory and inhibitory synaptic barrages (Crunelli and Hughes, 2010) or, alternatively, represent a network-independent intrinsic neuronal property, caused by a cyclical interplay of autonomous depolarizing and hyperpolarizing conductances (Blankenship and Feller, 2010). Such intrinsic pacemaker-like discharge has been implicated both in controlling rhythmic behaviors (Peña et al., 2004; Bucher et al., 2006; Koizumi and Smith, 2008; Tazerart et al., 2008) and in driving oscillatory circuits that play important roles in sensory perception, attention, memory formation, and decision making (Gutierrez et al., 2013). In the $\mathrm{MOB}$, sensory input evokes oscillatory network activity across a wide frequency range (Kay et al., 2009). Autonomous, episodic burst firing of external tufted (ET) cells within a small spectral window ( $\sim 0.2-10 \mathrm{~Hz}$; Hayar et al., 2004) has been attributed a role in setting sniff cycle-dependent glomerular synchrony (Hayar et al., 2005; Shao et al., 2009) and, consequently, distinct phase-locking of MOB principle neurons (Smear et al., 2011; Fukunaga et al., 2012). Whether aspects of sensory coding in the $\mathrm{AOB}$ are also affected by single cell/network rhythmicity, however, is unclear.

Here, we identify patterns of coordinated spontaneous activity among AOB mitral cells. We demonstrate that a subpopulation of these neurons reveals slow stereotypical rhythmic discharge both in vitro and in vivo. Among these neurons, a group of mitral cells is intrinsically rhythmogenic. Their autorhythmicity is driven by a precisely orchestrated ensemble of interdependent $\mathrm{Na}^{+}, \mathrm{Ca}^{2+}$, and $\mathrm{K}^{+}$conductances. The cyclic (in)activation of these three distinct conductances provides a mechanistic basis for infraslow intrinsic oscillations of remarkable periodicity in a subset of AOB projection neurons.

\section{Materials and Methods}

Animals. All animal procedures were approved by local authorities and were in compliance with European Union legislation (Directive 86/609/EEC) and recommendations by the Federation of European Laboratory Animal Science Associations. C57BL/6 mice (Charles River Laboratories) were housed in groups of both sexes [room temperature (RT); $12 \mathrm{~h} \mathrm{light/dark} \mathrm{cycle;} \mathrm{food} \mathrm{and} \mathrm{water} \mathrm{available} \mathrm{ad}$ libitum]. For in vivo recordings, sexually naive male BALB/c mice were used (Harlan Laboratories). All in vivo experiments were performed in compliance with the Hebrew University Animal Care and Use Committee.
Chemicals and solutions. The following solutions, labeled $S_{1}-S_{9}$, were used: $S_{1}$, HEPES buffered extracellular solution containing (in $\mathrm{mM}$ ) 145 $\mathrm{NaCl}, 5 \mathrm{KCl}, 1 \mathrm{CaCl}_{2}, 1 \mathrm{MgCl}_{2}, 10$ HEPES, pH 7.3 (adjusted with $\mathrm{NaOH}$ ), 300 mOsm (adjusted with glucose); $\mathrm{S}_{2}$, oxygenated $\left(95 \% \mathrm{O}_{2}, 5 \% \mathrm{CO}_{2}\right)$ artificial CSF (aCSF) containing (in $\mathrm{mm}$ ) $124 \mathrm{NaCl}, 26 \mathrm{NaHCO}_{3}, 3 \mathrm{KCl}$, $1.25 \mathrm{NaH}_{2} \mathrm{PO}_{4}, 1.3 \mathrm{MgSO}_{4}, 1.3 \mathrm{CaCl}_{2}, 10$ glucose, pH 7.3, $300 \mathrm{mOsm}$ (adjusted with glucose); $\mathrm{S}_{3}$, oxygenated $\left(95 \% \mathrm{O}_{2}, 5 \% \mathrm{CO}_{2}\right)$ cutting solution containing (in mM) 220 sucrose, $26 \mathrm{NaHCO}_{3}, 3 \mathrm{KCl}, 1.25 \mathrm{NaH}_{2} \mathrm{PO}_{4}$, 2.6 $\mathrm{MgSO}_{4}, 10$ glucose, $\mathrm{pH} 7.3,300$ mOsm (adjusted with glucose); $\mathrm{S}_{4}$, extracellular $\mathrm{Ba}^{2+}$ solution containing (in $\mathrm{mm}$ ) $100 \mathrm{NaCl}, 25$ tetraethylammonium chloride (TEA-Cl), 10 -aminopyridine, $10 \mathrm{BaCl}_{2}, 1 \mathrm{MgCl}_{2}$, 10 HEPES, 0.001 tetrodotoxin (TTX), pH 7.3 (adjusted with $\mathrm{HCl}$ ), 300 mOsm; $\mathrm{S}_{5}$, standard pipette solution containing (in $\mathrm{mM}$ ) $10.5 \mathrm{KCl}, 125$ $\mathrm{KOH}, 125$ gluconic acid, $2 \mathrm{MgCl}_{2}, 1$ EGTA, $0.3 \mathrm{CaCl}_{2}, 10$ HEPES, 2 Mg-ATP, $1 \mathrm{Na}$-GTP (free $\mathrm{Mg}^{2+}, 2 \mathrm{~mm}$; free $\mathrm{Ca}^{2+}, 130 \mathrm{~nm}$ ), $\mathrm{pH} 7.1$ (adjusted with $\mathrm{KOH}$ ), $290 \mathrm{mOsm} ; \mathrm{S}_{6}$, symmetrical chloride pipette solution containing (in mM) $143 \mathrm{KCl}, 2 \mathrm{KOH}, 1$ EGTA, $0.3 \mathrm{CaCl}_{2}, 10 \mathrm{HEPES}$, $2 \mathrm{Mg}$-ATP, $1 \mathrm{Na}-\mathrm{GTP}$ (free $\mathrm{Ca}^{2+}, 130 \mathrm{~nm}$ ), pH 7.1 (adjusted with $\mathrm{KOH}$ ), $290 \mathrm{mOsm} ; \mathrm{S}_{7}, \mathrm{Cs}^{+}$-based pipette solution containing (in mM) $125 \mathrm{glu}$ conic acid, $105 \mathrm{CsOH}, 20 \mathrm{NaOH}, 10.5 \mathrm{CsCl}, 2 \mathrm{MgCl}_{2}, 1 \mathrm{EGTA}, 0.3 \mathrm{CaCl}_{2}$, 10 HEPES, 2 Mg-ATP, $1 \mathrm{Na}-\mathrm{GTP}$ (free $\mathrm{Mg}^{2+}, 2 \mathrm{~mm}$; free $\mathrm{Ca}^{2+}, 130 \mathrm{~nm}$ ), pH 7.1 (adjusted with CsOH), 290 mOsm; $\mathrm{S}_{8}$, standard blocking solution containing 5\% normal bovine serum (Dianova), $0.8 \%$ Triton X-100, and $0.05 \% \mathrm{NaN}_{3}$ in $\mathrm{Ca}^{2+} / \mathrm{Mg}^{2+}$-free PBS (PBS ${ }^{-/-} ; 100 \mathrm{~mm}$ ); $\mathrm{S}_{9}$, standard staining solution containing $3 \%$ bovine serum albumin (IgG-free, protease-free), $0.05 \% \mathrm{NaN}_{3}$, and Alexa Fluor 488 or 633 streptavidin conjugate (1:800; Life Technologies) in $\mathrm{PBS}^{-1-}(100 \mathrm{~mm})$.

Free $\mathrm{Ca}^{2+}$ concentrations were calculated using WEBMAXC (http://web. stanford.edu/ cpatton/webmaxcE.htm). If not stated otherwise, chemicals were purchased from Sigma-Aldrich. Alexa Fluor hydrazide was purchased from Life Technologies; $\omega$-agatoxin IVA and SNX 482 were purchased from Tocris Bioscience; paxilline was purchased from Enzo Life Science; 2(3-carboxypropyl)-3-amino-6-(4 methoxyphenyl)pyridazinium bromide (gabazine), D-(-)-2-amino-5-phosphonopentanoic acid (AP5), 2,3-dioxo-6-nitro-1,2,3,4-tetrahydrobenzo[f] quinoxaline-7-sulfonamide (NBQX), $\omega$-conotoxin GVIA, and 4-ethylphenylamino-1,2-dimethyl-6-methylaminopyrimidinium chloride (ZD7288) were purchased from Abcam. Final solvent concentrations were $\leq 0.1 \%$. Solutions and pharmacological agents were applied either by bath or from air pressure-driven reservoirs via an eight-in-one multibarrel "perfusion pencil" (Science Products). Changes in focal superfusion (Veitinger et al., 2011) were software-controlled and, if required, synchronized with data acquisition by transistor-transistor logic input to $12 \mathrm{~V}$ DC solenoid valves using a TIB 14S digital output trigger interface (HEKA Elektronik).

Slice preparation. Mice were killed by brief exposure to a $\mathrm{CO}_{2}$ atmosphere and decapitation. The left and right olfactory bulbs were rapidly removed, separated with a razor blade, embedded in $4 \%$ low-gelling temperature agarose (VWR International), and placed in ice-cold oxygenated cutting solution $\left(\mathrm{S}_{3}\right)$. Parasagittal slices $(250 \mu \mathrm{m})$ were cut with a VT1000S vibratome (Leica Biosystems). Two slices per bulb, each including the $\mathrm{AOB}$, were transferred to a submerged, oxygenated storage container and allowed to recover for $\geq 1 \mathrm{~h}$ in aCSF $\left(\mathrm{S}_{2}\right)$. Slices were then stored at RT until use.

Histology and immunochemistry. For immunohistochemical labeling of AOB sections, olfactory bulbs were fixed in $4 \%(\mathrm{w} / \mathrm{v})$ paraformaldehyde (PFA) in $\mathrm{PBS}^{-1-}\left[10 \mathrm{~mm}, \mathrm{pH} 7.4\left(3 \mathrm{~h}, 4^{\circ} \mathrm{C}\right)\right]$ and subsequently cryoprotected in $\mathrm{PBS}^{-1-}$ containing $30 \%$ sucrose $\left(\geq 24 \mathrm{~h}, 4^{\circ} \mathrm{C}\right)$. Samples were embedded in Tissue Freezing Medium (Leica Biosystems), sectioned at $20 \mu \mathrm{m}$ on a Leica CM1950 cryostat (Leica Biosystems), and mounted on Superfrost Plus slides (Menzel). Next, sections were incubated in $4 \%$ PFA $\left(15 \mathrm{~min}, 4^{\circ} \mathrm{C}\right)$, washed several times in $\mathrm{PBS}^{-1-}$, and then incubated $(1 \mathrm{~h}, \mathrm{RT})$ in $\mathrm{PBS}^{-1-}$-based blocking solution containing $0.8 \%$ Triton $\mathrm{X}-100,0.05 \% \mathrm{NaN}_{3}$, and normal bovine serum. Primary antibodies were anti-Slo1 ( $\mathrm{K}_{\mathrm{Ca}} 1.1,1: 500$; Alomone Labs), anti-Slo $\beta 4$ (1:100; Alomone Labs), and anti-Ca 2.3 (1:100; Alomone Labs). Cryosections were incubated with primary antibodies $\left(19 \mathrm{~h}, 4^{\circ} \mathrm{C}\right)$ in a dark humidified chamber. After washing in $\mathrm{PBS}^{-1-}(3 \times, 10 \mathrm{~min})$, sections were incubated in $\mathrm{PBS}^{-1-}(1 \mathrm{~h}, \mathrm{RT})$ containing Alexa Fluor-conjugated secondary antibodies (1:500; Life Technologies). Excess antibodies were 
removed by washing $(5 \times, 10 \mathrm{~min})$. Fluorescent images were taken using an upright fixed-stage scanning confocal microscope (Leica TCS SP5 DM6000 CFS, Leica Microsystems) equipped with a $20 \times 1.0$ numerical aperture water-immersion objective (HCX APO L, Leica Microsystems). To control for nonspecific staining and to demonstrate antibody specificity, we performed (1) antigen preadsorption controls and (2) experiments in which the primary antibodies were omitted in parallel with each procedure. Nuclei were counterstained using 1, 5-bis $\{[2$-(di-methylamino)ethyl $]$ amino $\}$-4, 8-dihydroxyanthracene-9, 10dione (DRAQ5, 1:200; ThermoFisher Scientific). Digital images were uniformly adjusted for brightness and contrast using Adobe Photoshop CS6 (Adobe Systems).

For immunoblotting, both $\mathrm{AOB}$ and control tissue were homogenized in lysis buffer $\left(100 \mu \mathrm{l}, 0.1 \%\right.$ Triton $\left.\mathrm{X}-100,4^{\circ} \mathrm{C}\right)$ in the presence of Complete Mini protease inhibitor mixture tablets (Roche). The homogenate was sonicated and centrifuged for $10 \mathrm{~min}\left(4^{\circ} \mathrm{C}, 1000 \times g\right)$. The supernatant was resuspended in lysis buffer and protein concentration was determined (BioPhotometer Plus, Eppendorf). Thirty microliters of Laemmli buffer (20\% glycerol, 4\% SDS, $125 \mathrm{~mm}$ Tris- $\mathrm{HCl}$, and $0.02 \%$ bromphenol blue, $\mathrm{pH}$ 6.8) was added and equal amounts of protein were fractionated by SDS-PAGE. Separated proteins were transferred using a Bio-Rad Criterion Blotter wet-blotting system. Membranes were washed, stained with Ponceau $S$ to control for protein transfer, and again washed with TBST (61 mm Tris- $\mathrm{HCl}, 88 \mathrm{~mm} \mathrm{NaCl}, 0.1 \%$ Tween $20, \mathrm{pH}$ 7.5). Blocking was performed in 5\% non-fat dry milk/TBST overnight. Blots were then incubated in $2.5 \%$ non-fat dry milk/TBST $\left(1 \mathrm{~h}, 4^{\circ} \mathrm{C}\right)$ with anti-Slo1 (1:200; Alomone Labs) and anti-Slo $\beta 4$ (1:50; Alomone Labs) antibodies. Membranes were then washed $(4 \times 15 \mathrm{~min})$ in TBST and incubated with horseradish peroxidase-conjugated goat anti-rabbit IgG (Bio-Rad; 1 h, RT, 1:5000) in 2.5\% non-fat dry milk/TBST. Blots were again washed in TBST $(4 \times 15 \mathrm{~min})$ and antibody binding was detected using $2.5 \mathrm{ml}$ of Lumi-Light solution (Roche).

For post hoc visualization, 3D reconstruction, and morphometric analysis of $\mathrm{AOB}$ mitral cells diffusion-loaded ( $\geq 20 \mathrm{~min}$ ) with biocytin during whole-cell patch-clamp recordings, slices were kept for another $15 \mathrm{~min}$ in the recording chamber to wash out excess biocytin (Marx et al., 2012). AOB slices were then fixed in $4 \%$ PFA in $\mathrm{PBS}^{-1-}\left[0.1 \mathrm{M}\right.$; $\mathrm{pH} 7.4\left(4^{\circ} \mathrm{C}\right.$, $\geq 12 \mathrm{~h})]$. Next, slices were washed $(4 \times 10 \mathrm{~min})$ in $\mathrm{PBS}^{-1-}$ and incubated in blocking/permeabilization solution $\left(\mathrm{S}_{8} ; 4^{\circ} \mathrm{C}, 90 \mathrm{~min}\right)$. Subsequently, biocytin-filled neurons were stained in a dark humidified chamber $\left(\mathrm{S}_{9}\right.$; $60 \mathrm{~min}, \mathrm{RT}$ ) with fluorophore-conjugated streptavidin. After washing in $\mathrm{PBS}^{-1-}(4 \times 10 \mathrm{~min})$, slices were mounted on slides and coverslipped. Confocal fluorescent $z$-stack images were taken using an upright fixedstage scanning confocal microscope (TCS SP5 DM6000CFS, Leica Microsystems) equipped with a $20 \times / 1.0$ numerical aperture waterimmersion objective (HCX APO L, Leica Microsystems). Alexa Fluor 488 or 633 streptavidin conjugate were excited using the $488 \mathrm{~nm}$ line of an argon laser or a $633 \mathrm{~nm}$ HeNe laser, respectively. Rendering of 3D data and morphometric measurements were performed using Imaris 8.0 software (Bitplane).

In vivo recordings. Electrophysiological recordings of $\mathrm{AOB}$ neurons were performed as previously described in detail (Ben-Shaul et al., 2010; Cichy et al., 2015). Mice were anesthetized with $100 \mathrm{mg} / \mathrm{kg}$ ketamine and $10 \mathrm{mg} / \mathrm{kg}$ xylazine and a tracheotomy was performed using a polyethylene tube (inner diameter, $0.76 \mathrm{~mm}$; outer diameter, $1.22 \mathrm{~mm}$ ). Though not used during the recordings presented here, a cuff electrode was placed on the sympathetic nerve trunk. Incisions were closed and the mouse was placed in a custom-built stereotaxic apparatus where anesthesia was maintained throughout the entire experiment $(0.5-1 \%$ isoflurane in $\mathrm{O}_{2}$ ). A craniotomy was made immediately rostral to the rhinal sinus, the dura was removed around the penetration site, and electrophysiological probes were advanced into the $\mathrm{AOB}$ using an electronic micromanipulator (MP-285, Sutter Instruments). All recordings were made with 32-channel multisite electrodes (A4x8-5mm-100-200-5 177, NeuroNexus Technologies). Spontaneous neuronal activity was recorded without vomeronasal stimulation for 3-10 min. Before each recording, electrodes were dipped in fluorescent dye (DiI; Invitrogen) and targeting of the AOB external cellular layer was confirmed from electrode tracts post mortem. During the experiment, large well isolated spikes were found exclusively when electrode tracks traversed the AOB external cellular layer. By contrast, negligible neural activity was observed from electrode tracks located in the granule cell layer. Recordings from MOB units were identified by both electrode tracks and signal-response patterns, and were thus removed from the analysis. Using an RZ2 processor, PZ2 preamplifier, and two RA16CH head-stage amplifiers (TuckerDavis Technologies), neuronal activity was sampled at $25 \mathrm{kHz}$ and bandpass filtered at $0.3-5 \mathrm{kHz}$. Candidate spike events were derived from continuous electrode data using the Matlab thselect function with a minimaxi criterion. The threshold was set conservatively to avoid loss of candidate spikes. Because each shank of the probe contains eight recording sites, each spike event is defined by eight simultaneously measured waveforms (spanning $3.5 \mathrm{~ms}$; detected at any site). Then, for each recording site, we calculated the first two principal components of all recorded waveforms. Each spike event was then characterized according to its projections on the first two principal components of each of the eight channels per shank. Thus, each spike waveform was defined by 16 numbers. These numbers were then fed to the automatic spike-sorting algorithm KlustaKwik (Harris et al., 2000), which assigned each event to one of several clusters. Clusters were then manually examined and adjusted using the Klusters program (Hazan et al., 2006). This latter control procedure is required since the KlustaKwik function tends to overseparate clusters. Criteria for cluster evaluation included the spike waveforms themselves, their projections on the principal component space, and the interspike interval (ISI) histogram. Spike clusters were defined as single units if (1) they had a distinct spike shape, (2) they were fully separated from both the origin (noise) and other clusters in $\geq 1$ principal component projection, and (3) their ISI histogram demonstrated a clear trough of $\geq 10 \mathrm{~ms}$ duration around time 0 . If a cluster was composed of $>1$ single unit, it was designated as multiunit activity and excluded from the analysis. All spike-sorting procedures (except KlustaKwik and Klusters) were implemented using custom-written Matlab code.

In vitro electrophysiology. Olfactory bulb slices were transferred to a recording chamber (Luigs \& Neumann), positioned with stainless steel anchors, and visualized using an upright fixed-stage video-microscope (DM6000FS, Leica Microsystems) equipped for infrared-optimized differential interference contrast. Slices were continuously superfused with oxygenated $\mathrm{S}_{2}\left(\sim 3 \mathrm{ml} / \mathrm{min}\right.$, gravity flow, $\left.25^{\circ} \mathrm{C}\right)$. Bath temperature was measured and controlled using the temperature controller TC07 and the PTC Minibath Chamber IV Plus Upgrade kit (Luigs \& Neumann). Neurons were visualized using a $5 \times(\mathrm{N}$ Plan $5 \mathrm{x} / 0.12)$ and $25 \times(\mathrm{HCX}$ IRAPO $\mathrm{L} 25 \mathrm{x} / 0.95 \mathrm{~W})$ objective, a three-position magnification changer $(0.35 \times$, $1.25 \times$, and $4.0 \times$ ) and a cooled CCD camera (DFC360FX, Leica Microsystems). Patch pipettes (5-8 M $\Omega$ ) were pulled from borosilicate glass capillaries (outer diameter, $1.50 \mathrm{~mm}$; inner diameter, $0.86 \mathrm{~mm}$; Science Products) on a PC-10 micropipette puller (Narishige Instruments), firepolished (MF-830 Microforge, Narishige Instruments), and filled with pipette solution $\left(\mathrm{S}_{5}-\mathrm{S}_{7}\right.$, depending on experimental design). Alexa Fluor 488 hydrazide $(20 \mu \mathrm{M})$ and, in some recordings, biocytin [0.3\% (w/v)] was routinely added to the pipette solution to enable on-line evaluation of cell morphology and post hoc 3D reconstruction of recorded neurons, respectively. Neither chemical showed an evident effect on mitral cell electrophysiology. An agar bridge $(150 \mathrm{~mm} \mathrm{KCl})$ connected the reference electrode and bath solution. An EPC-10 USB amplifier controlled by Patchmaster 2.67 software (HEKA Elektronik) was used for data acquisition. We monitored and compensated pipette and membrane capacitance $\left(C_{\mathrm{mem}}\right)$ as well as series resistance. Only neurons exhibiting relatively low $(<30 \mathrm{M} \Omega)$ and stable access resistances were used for analysis. Liquid junction potentials were calculated using JPCalcW software (Barry, 1994) and corrected on-line. Signals were low-pass filtered [analog three-pole and four-pole Bessel filters $(-3 \mathrm{~dB})$; adjusted to onequarter to one-fifth of the sampling rate $(10 \mathrm{kHz})]$. If not stated otherwise, holding potential $\left(V_{\text {hold }}\right)$ was $-70 \mathrm{mV}$. All electrophysiological data were recorded at RT. Mitral cells were identified according to their location [residing in the external cellular layer between the AOB glomerular layer and the lateral olfactory tract (Larriva-Sahd, 2008)], soma size (large somata; average $C_{\text {mem }}, 14.5 \pm 0.4 \mathrm{pF}$ ), and dendritic morphology (multiple apical/primary dendrites that terminate as tufts in the glomerular layer). "Loose-patch" recordings were performed from intact mitral 
cell somata to prevent dialysis of intracellular components. Action potential-driven capacitive currents were recorded in loose-seal cellattached configuration (seal resistance, 30-150 $\mathrm{M} \Omega$; pipettes filled with $\mathrm{S}_{1}$ ). Spikes were analyzed using Igor Pro functions (SpAcAn, written by Guillaume Dugué and Charly Rousseau) for detection and analysis of spontaneous events by a threshold detection algorithm. Passive membrane properties [i.e., input resistance $\left(R_{\text {input }}\right), C_{\text {mem }}$, and membrane time constant $\left.\left(\tau_{\text {mem }}\right)\right]$ were obtained immediately after membrane rupture. Treated, to a first approximation, as a "biological constant" with a value of $\sim 1 \mu \mathrm{F} / \mathrm{cm}^{2}$ (Gentet et al., 2000), $C_{\text {mem }}$ was determined using a square-pulse $(5 \mathrm{mV}, 10 \mathrm{~ms})$ routine. $R_{\text {input }}$ at the mitral cell soma was determined by measuring the steady-state voltage response to a hyperpolarizing current step of $-20 \mathrm{pA}$. Linear passive voltage responses were also used to estimate $\tau_{\text {mem }}$ from monoexponential fits to the voltage responses (from onset to steady state). General action potential parameters were calculated from averaged spike waveforms. Spike amplitude was measured as the threshold-to-peak distance, spike duration was calculated as the full duration at half-maximum (FDHM), and spike-generating kinetics were measured as the time-to-peak. All electrophysiological in vitro experiments used slices from young adults of either sex. We did not observe obvious gender-dependent differences.

Modeling. The model design and specification was set up in neuroConstruct software (Gleeson et al., 2007). neuroConstruct facilitates the building and validation of models conforming to the NeuroML specification (www.neuroml.org). Model scripts were generated at multiple stages during the development process by neuroConstruct to run simulations using the Neuron simulator software (Hines and Carnevale, 1997, 2001). Simulator software contains solvers that run all the differential equations that are spatially distributed within the morphological framework of the model at a specified time step. It also allows the output of these differential equations to be recorded at specified locations and for specified parameters.

For model development, the digitized 3D reconstruction of a representative intrinsically oscillating AOB mitral cell was chosen. Morphology parameters were saved as a hoc file and imported into neuroConstruct. Compartments were separated into groups (soma, dendrites, axon) for specifying channel allocation.

The model's specific passive parameters were tuned to target mean experimental measurements/estimates, such as somatic $R_{\text {input }}, \tau_{\text {mem }}$, and $C_{\text {mem }}$. Based on simulated somatic current injections (70 pA, $400 \mathrm{~ms}$ ), $R_{\text {input }}$ was calculated as follows: $\Delta V_{\text {mem }} / I_{\text {inject }}$, with $V_{\text {mem }}$ defined as cell membrane potential and $I_{\text {inject }}$ defined as injection current. $\tau_{\text {mem }}$ Was estimated by monoexponential fits using the Octave expfit function (http://octave.sourceforge.net/). Then, a simulated voltage-clamp test pulse ( $5 \mathrm{~ms}, 5 \mathrm{mV}, 20 \mathrm{M} \Omega$ ) was applied to the soma and $C_{\mathrm{mem}}$ was estimated by fitting an exponential to the capacitive transient (Octave expfit). Iterations were repeated until passive model parameters replicated experimental values. The passive parameters were as follows: $C_{\text {mem }}=0.79 \mu \mathrm{F} \mathrm{cm}^{-2} ; R_{\text {mem }}=59,524 \Omega \mu \mathrm{m}^{-2}$; and $R_{\text {input }}=560 \Omega \mathrm{cm}$.

New models for outward-rectifying $\mathrm{K}^{+}$-channel current $\left(I_{\mathrm{Kdr}}\right)$, transient $\mathrm{K}^{+}$-channel current $\left(I_{\mathrm{KA}}\right)$, persistent $\mathrm{Na}^{+}$current $\left(I_{\mathrm{NaP}}\right)$, and voltage-gated $\mathrm{Ca}^{2+}$ current $\left(I_{\mathrm{CaV}}\right)$ were developed from current-voltage $(I-V)$ plots, steady-state plots, and time-course datasets for activation, inactivation, and deactivation measured in voltage-clamp experiments. These models were used in combination with previously published models for transient $\mathrm{Na}^{+}$current $\left(I_{\mathrm{NaT}}\right.$; Migliore et al., 2005) and big conductance $\mathrm{K}_{\mathrm{Ca}}(\mathrm{BK})$ current $\left(I_{\mathrm{BK}}\right.$; Maex and De Schutter, 1998). Ionic reversal potentials were (in millivolts) as follows: $E_{\text {leak }}=-74.1, E_{\mathrm{Na}}=$ 67, $E_{\mathrm{K}}=-86.5$, and $\mathrm{E}_{\mathrm{Ca}}=80$. All equations and channel densities $\left(G_{\max }\right)$ for each model are found at https://github.com/Simon-at-Ely/ Channel_Kinetics/blob/master/AccessoryOlfactoryBulb/MitralCell/ipyt hon/MultipleChannelModel/iAMT_model_specification.ipynb (any tuning adjustments have been highlighted in red or blue).

Data analysis. All in vitro data were obtained from independent experiments performed on $\geq 3 \mathrm{~d}$ using $\geq 3$ different animals. Individual numbers of cells/experiments $(n)$ are denoted in the figure and/or captions. If not stated otherwise, results are presented as means \pm SEM. Statistical analyses were performed using paired or unpaired $t$ tests, one-way ANOVA with Tukey's HSD post hoc test, Mann-Whitney $U$ tests, Wil- coxon signed-rank tests, or Kruskal-Wallis tests (as dictated by data distribution and experimental design). Tests and corresponding $p$ values that report statistical significance $(\leq 0.05)$ are individually specified in the figure legends. Data were analyzed off-line using FitMaster 2.67 (HEKA Elektronik), Imaris 8.0 (Bitplane), IGOR Pro 6.3 (WaveMetrics), Matlab (Mathworks), and Excel 2013 (15.0.4779.1001, Microsoft) software. Activation curves were fitted by the Boltzmann equation to calculate the $V_{\text {mem }}$ of half-maximal activation $\left(V_{1 / 2}\right)$. Time constants $(\tau)$ were calculated by fitting individual traces to monoexponential functions $I_{(\mathrm{t})}$ $=I_{1}[\exp (-t / \tau)]+I_{0}$. Linear correlation of two parameters was analyzed by calculating the Pearson correlation coefficient using IGOR Pro's linear correlation procedure. Data fitting for model development was carried out using IPython Notebook (ipython.org/notebook.html) and a least-square fitting method.

To account for the variability in single-unit firing rates obtained from in vivo recordings, unit classification required statistical analysis. Bursting activity was defined statistically as follows. First, for each unit, an expected ISI distribution assuming random independent (Poisson) spiking was derived. Poisson distribution is defined by a single parameter $\lambda$, which corresponds to that unit's observed average firing rate, calculated over the entire recording period. From this distribution, the median ISI value for each unit (i.e., intervals smaller or larger than this interval were equally likely) was derived. A burst was defined as a sequence of $\geq 4$ consecutive spikes separated by intervals smaller than the median ISI (Fig. $1 \mathrm{Ei}-\mathrm{Hi}$, red horizontal bars). A unit was classified as "nonbursting" if $<50 \%$ of all spikes occurred in bursts. By contrast, a unit was classified as "bursting" if (1) $>50 \%$ of all spikes occurred in bursts, and (2) that unit's ISI distribution was significantly different ( $p<0.05$; two-sample Kolmogorov-Smirnov test) from the expected Poisson distribution under the null hypothesis of random firing at the same mean firing rate. For additional classification of (ir)regularity, spike time autocorrelation histograms $(\mathrm{ACHs})$ were calculated for each unit across multiple time periods: 5, 10, 20, 30, 60, 90, and 120 s. Each period was divided into 200 equal bins $(5 \mathrm{~s} \mathrm{ACH} \triangleq 25 \mathrm{~ms}$ bins, $120 \mathrm{~s} \mathrm{ACH} \triangleq 600 \mathrm{~ms}$ bins). Based on each unit's autocorrelograms, we determined $\mathrm{ACH}$-specific trough indices. The trough index (TI) was defined as follows: $T I=\frac{C V}{N_{\text {cross }}}$, where $\mathrm{CV}$ is the coefficient of variation of the autocorrelogram, and $N_{\text {cross }}$ is the number of times that the autocorrelogram crosses its mean value. The TI is designed to capture numerically what is intuitively perceived as an oscillatory ACH (Moore et al., 1966). Thus, the TI attains high values if an autocorrelogram exhibits large fluctuations from its mean that are concentrated in a small number of peaks, a feature that is associated with robust oscillatory activity. By contrast, flat $\mathrm{ACHs}$ or autocorrelograms with many deviations from the mean are associated with low TI values. The rationale for examining multiple autocorrelograms per unit was to detect oscillatory activity over a range of time scales. To identify the time scale exhibiting the strongest oscillatory activity, we compared, for each neuron separately, the set of TIs for all autocorrelograms. For comparison across time scales, we used a standardized TI, defined as TI - median $(T I)$

$S T D(T I)$. This standardization was performed across all units for each time scale separately. Thus, potential oscillatory activity was classified by a single number, i.e., the maximal standardized TI across all time periods. One caveat to the use of the TI as a classifier of oscillatory activity is that nonstationary firing (e.g., strong transient activity) could result in large TI values. From visual inspection of ISI distributions and ACHs, we found that these cases were associated with small $N_{\text {cross }}$ values. Therefore, we excluded autocorrelograms of $N_{\text {cross }}<9$. Based on the above parameters, bursting units were categorized as oscillatory/regular if their maximal standardized TI was $>0.2$.

In addition to each unit's classification as either nonbursting, irregular bursting, or regular bursting (i.e., oscillating), oscillatory firing patterns were further characterized by various statistics. These included the number and duration of bursts as well as the number and frequency of spikes within bursts. 
A

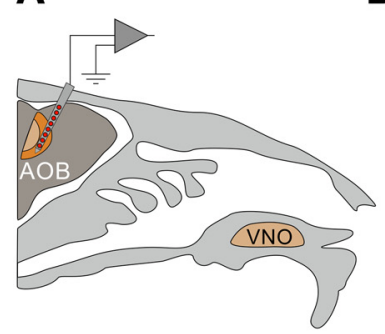

B

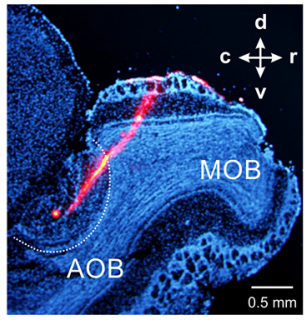

D (i)
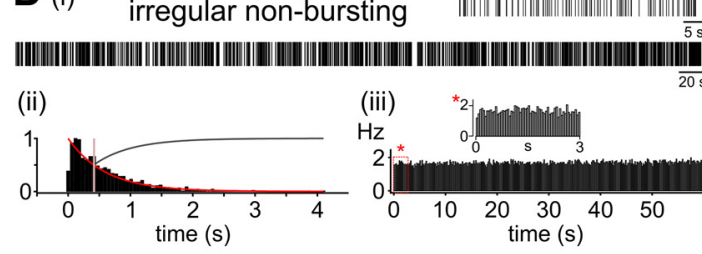

$F_{\text {(i) }}$ oscillating

i i i i i i i ii i ii

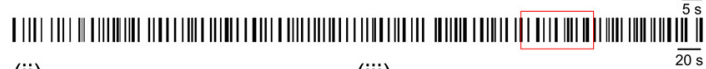
(ii)

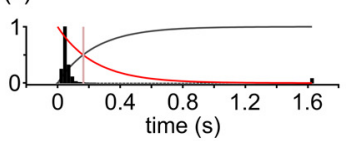

(iii)

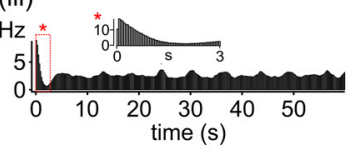

C

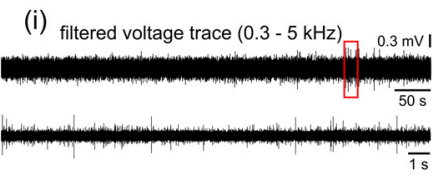

(iii)

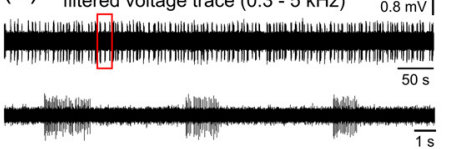

(ii)

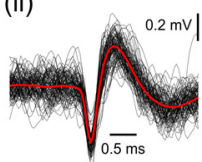

(iv)

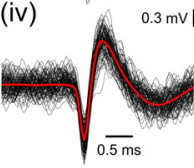

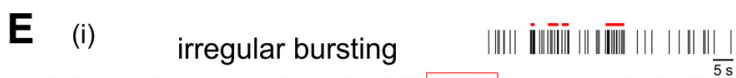

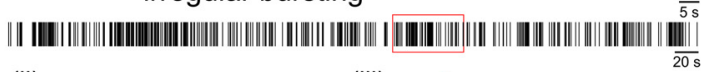
(ii)
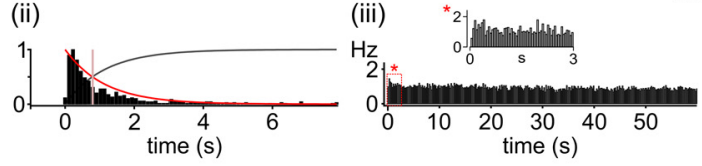

G (i)

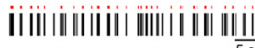
| || ||||||||||||||||||||||||||||||||||||||||||||||||||||||||||||||||||||||||||||||||||||||||||||||||||||||||||||||||||||||||||||||||||||||||||||||||||||||||||||||||||||| (ii)

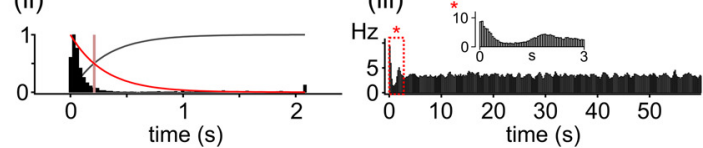

$H_{\text {(i) }}$

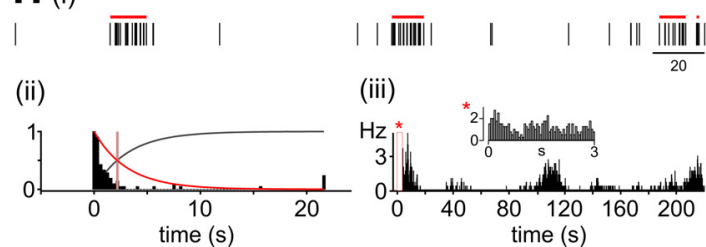

I
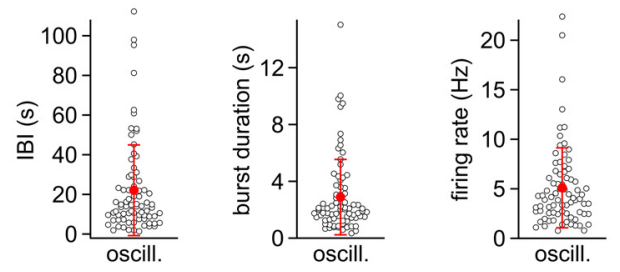

$\mathbf{J}_{\text {(i) }}$

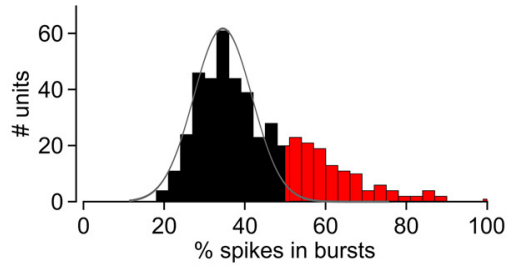

(ii)

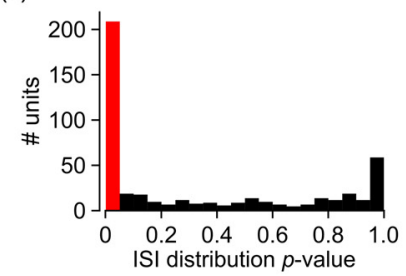

(iii)

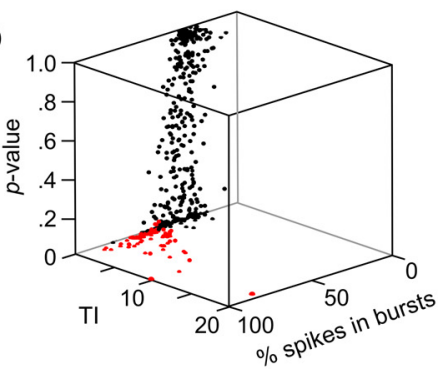

Figure 1. Firing patterns of $A O B$ neurons in vivo. $A$, Schematic drawing illustrating the multisite recording electrode arrangement in the mouse AOB. B, Digital photomicrograph reconstructing the location of a Dil-labeled 32-site recording electrode from a single fluorescent tract (red) in a $30 \mu \mathrm{m}$ sagittal section of the olfactory bulb (nuclear staining; blue; DAPI). Dashed white line delimits the AOB. The electrode was accurately targeted to the AOB mitral cell layer. Ci, Ciii, Example extracellular recordings of spontaneous activity (10 min duration; $0.3-5 \mathrm{kHz}$ bandpass filtered) in the AOB of anesthetized mice. Red boxes illustrate 20 s time windows shown at an enlarged scale below. Cii, Civ, Off-line spike waveform sorting isolated single-unit activity from two presumptive mitral cells with irregular and bursting discharge, respectively, clustered from the multiunit activity recordings displayed in Ci and Ciii. Ensembles of overlaid spike waveforms (black) and average spike shapes (red) are shown. $\mathbf{D}-\boldsymbol{H}$, Raster plots of spike times (Di, Ei, Fi, Gi, Hi) recorded from five individual representative AOB neurons in vivo. The corresponding ISI distribution (Dii, Eii, Fii, Gii, $\boldsymbol{H i i )}$ and autocorrelation (Diii, Eiii, Fiii, Giii, Hiiii) histograms enable the classification of neurons as either irregular nonbursting (D; corresponding to $(\boldsymbol{C}$, Cii), irregular bursting (E), or oscillating ( $\boldsymbol{F}-\boldsymbol{H}$; F corresponds to Ciii, Civ). Dii, Eii, Fii, Gii, Hii, ISI histograms superimposed with the probability (red curve) and cumulative probability (gray curve) functions, corresponding to random Poisson spiking with the same mean rates. The median ISI interval $\left(\mathrm{ISI}_{0.5}\right)$ is indicated by the light red vertical line. Note that regularity [or the lack thereof $(\boldsymbol{D}, \boldsymbol{E})$ ] is mirrored by the shape of the $\mathrm{ACH}(\boldsymbol{F}-\boldsymbol{H}$; $200 \mathrm{~ms}$ bin width). Insets, Autocorrelograms ( 3 s duration; $50 \mathrm{~ms}$ bin width) show narrow initial peaks close to zero $(\boldsymbol{E}-\boldsymbol{G})$, indicative of bursting units. Red asterisks $\left({ }^{*}\right)$ and boxes mark the time windows of either spike times (Di, Ei, Fi, Gi, Hi) or autocorrelograms (Diii, Eiii, Fiii, Giii, Hiiii) displayed at an expanded time scale; red horizontal bars in $\mathbf{E i}$, Fi, Gi, and $\mathbf{H i}$ denote epochs detected as bursts (see Materials and Methods). $I$, Scatter dot plots depicting the distribution of IBIs, burst durations, and within-burst firing rates for all bursts recorded from 78 oscillating units in vivo. Average values are shown as means $\pm S D$ (red): $I B l s, 22.1 \pm 22.8 \mathrm{~s}$ (median, $14.0 \mathrm{~s}$ ); durations, $2.9 \pm 2.7 \mathrm{~s}$ (median, $2.0 \mathrm{~s}$ ); firing rates, $5.1 \pm 4.0 \mathrm{~Hz}$ (median, $4.0 \mathrm{~Hz}$ ). J, Histogram plots of various descriptors of firing behavior. Diagrams depict the percentage of a unit's spikes that occurred within a burst (Ji), the deviation of a unit's ISI distribution from random firing (Jii), and the relation of both parameters to a unit's discharge regularity as indicated by its TI (Jiii; 3D scatter plot). In Jiii, units classified as oscillating are shown in red. Note the skewed distribution of burstiness (Ji; single peak fitting of a Gaussian function reveals a population of units with $\geq 50 \%$ spikes in bursts; red bars), the overrepresentation of both large and small $p$ values (Jii; red bar denotes $p<0.05$ ), and the cluster of red dots within the 3D parameter space (Jiii). 


\section{Results}

\section{Slow oscillatory bursting of AOB neurons in vivo}

Brain circuit computations are not only determined by sensory input, but also by intrinsically generated spatiotemporally structured patterns of spontaneous activity (Romano et al., 2015), both at the single-neuron and network levels. As information about spontaneous $\mathrm{AOB}$ activity is lacking, we performed in vivo recordings from the $\mathrm{AOB}$ mitral cell layer of anesthetized mice (Fig. $1 A-C$ ). We continuously monitored spontaneous multiunit activity of $\mathrm{AOB}$ neurons and validated putative single units by feature-based clustering (Fig. 1C). Inspection of spike trains over time revealed large firing-pattern heterogeneity in $\mathrm{AOB}$ neurons, ranging from apparently random (Fig. $1 \mathrm{C}$ ) to more regular firing (Fig. 1Ciii).

Based on these initial findings, we next quantified and classified the observed patterns (Fig. $1 D-H$ ). Consideration of multiple measures, including deviation from Poissonian spiking, burst-firing parameters, autocorrelation analysis, and each unit's TI (see Materials and Methods), revealed two different discharge categories: 339 of 466 (72.8\%) units were classified as irregular nonbursting (Fig. 1D), whereas 127 of 466 (27.2\%) units were classified as bursting (Fig. $1 E-H$ ). Among the bursting subpopulation of AOB neurons, 49 (10.5\%) displayed irregular burst firing characterized by an exponential decay of the ISI histogram and the lack of pronounced autocorrelogram "side" peaks. These units were classified as irregular bursting neurons (Fig. 1E). By contrast, $78(16.7 \%)$ bursting neurons showed highly rhythmic oscillatory discharge with prominent ISI and $\mathrm{ACH}$ peaks, corresponding to large TI values (see Materials and Methods). These neurons were classified as oscillating (Fig. $1 F-H$ ). Within this subpopulation of oscillating AOB neurons, individual discharge patterns were heterogeneous and, accordingly, interburst intervals (IBIs), burst durations, and firing rates were highly variable (Fig. 1I). IBIs ranged from 1.4 to $112.2 \mathrm{~s}$ and bursts lasted for $\leq 15.0$ s. The non-normal distribution of these values indicates the absence of a single characteristic rhythm governing AOB unit oscillations. In general, the activity of oscillating neurons was markedly increased compared with previously observed low baseline rates $(1-2 \mathrm{~Hz}$ ) of irregularly firing neurons (Luo et al., 2003; Ben-Shaul et al., 2010). To identify whether the characteristics of oscillating units define a distinct subpopulation of $\mathrm{AOB}$ neurons or they instead represent one extreme of a continuous and normally distributed dataset, we plotted histograms of burstiness (Fig. 1Ji), deviation from Poissonian spiking (Fig. 1Jii), and regularity (Fig. 1Jiii) for the entire sample population ( $n=466)$. Our analyses indicate that oscillating AOB neurons indeed form a distinct group. Together, these results demonstrate that rhythmic patterns of slow oscillatory activity characterize a subpopulation of $\mathrm{AOB}$ neurons in vivo.

\section{A subpopulation of $\mathrm{AOB}$ mitral cells displays slow spontaneous oscillations}

AOB neuron oscillatory discharge may result from interactions within an intact network and potential top-down modulation or, alternatively, from intrinsic rhythmogenic properties of individual neurons. To resolve the mechanistic basis of mitral cell rhythmicity and avoid the experimental drawbacks that complicate the biophysical interpretation of in vivo whole-cell patch-clamp data (Maier et al., 2011), we turned to an in vitro model. We recorded spontaneous activity from individual $\mathrm{AOB}$ mitral cells in sagittal sections of the mouse olfactory bulb (Fig. $2 A$ ). When continuously monitoring mitral cell $V_{\text {mem }}$ for prolonged periods of time under control conditions ( 0 pA current injection; $\mathrm{S}_{2}, \mathrm{~S}_{5}$; see Ma- terials and Methods), the vast majority of neurons generated spontaneous discharge [308 of 324 cells; resting $V_{\text {mem }}\left(V_{\text {rest }}\right)=$ $-73.2 \pm 0.6 \mathrm{mV}$; firing rate, $2.9 \pm 0.4 \mathrm{~Hz}$; means $\pm \mathrm{SEM}]$. Similar to our in vivo findings, AOB mitral cells displayed one of two distinct activity patterns (Fig. $2 B$ ): either irregular firing with no apparent periodicity (irregular discharge; 105 of 308 cells; $V_{\text {rest }}$ $=-71.9 \pm 0.7 \mathrm{mV}$; Fig. $2 \mathrm{Bi}$ ) or "phasic" firing patterns with alternating periods of activity and silence (oscillatory discharge; 203 of 308 cells; $V_{\text {rest }}=-74.1 \pm 0.8 \mathrm{mV}$; Fig. 2 Bii). These slow oscillations of recurring up and down states $(-63.9 \pm 2.5$ vs $-74.5 \pm 3.7 \mathrm{mV}$, mean $\pm \mathrm{SD}$ ) usually remained stable throughout the recording ( $\leq 60 \mathrm{~min}$ ). Typically, bursts of action potentials were superimposed on the slow depolarizing envelope (burst duration, $6.0 \pm 5.3 \mathrm{~s}$; IBI, $11.3 \pm 7.6 \mathrm{~s}$; within-burst firing rate, $4.2 \pm 2.3 \mathrm{~Hz}$, mean $\pm \mathrm{SD}$ ). Essentially identical patterns of spontaneous activity were observed when we recorded mitral cell activity in "loose-seal" cell-attached configuration $(n=39)$ to prevent dialysis of cytosolic components and maintain unperturbed $V_{\text {rest }}$ (Fig. 2Biii). As a measure of regularity and bursting behavior (Moore et al., 1966), we inspected the ISI distribution and the ACHs (Fig. 2C-F). Figure $2 C$ exemplifies an irregular nonbursting neuron, whereas oscillatory mitral cells are depicted in Figure $2 D-F$. While discharge periodicity for individual cells was strong, patterns were heterogeneous across the population, revealing no predominant rhythm. We then asked whether these two patterns of spontaneous activity correlate with distinct morphological phenotypes (Fig. 2G). Volume-rendered 3D reconstructions of individual biocytin-filled mitral cells (Fig. 2Gi,Gii) revealed large polymorphic somata and several branched primary dendrites that terminate as multiple tufts within the homonymous AOB half (Wagner et al., 2006). However, morphometric analysis documented no obvious morphological differences between irregularly firing and oscillating neurons (Fig. 2Giii). Together, these data demonstrate that, both under in vivo and in vitro conditions, infraslow oscillatory discharge represents the default activity pattern of a substantial population of AOB mitral cells.

\section{A group of AOB mitral cells are intrinsically rhythmogenic}

Neural rhythmogenesis is either a consequence of network activity and thus results from regular recurrence of excitatory and inhibitory synaptic barrages (Crunelli and Hughes, 2010) or, alternatively, oscillations are generated intrinsically by the repetitive, rhythmic discharge of pacemaker-like neurons (Blankenship and Feller, 2010). To distinguish between these mechanisms, we tested whether spontaneous oscillations in AOB mitral cells depend on synaptic drive. Pharmacological inhibition of GABAergic synaptic transmission did not qualitatively affect rhythmic discharge (Fig. $3 A$ ). Furthermore, when both GABAergic and glutamatergic fast synaptic transmission were blocked (Fig. $3 B, C$ ), stable oscillations persisted in a substantial fraction of AOB mitral cells ( 43 of 185 cells; $23.2 \%$ ). While selective block of inhibitory input altered some oscillation parameters (Fig. 3D), complete isolation from fast synaptic transmission did not change oscillatory patterns in those $\mathrm{AOB}$ neurons that proved resistant to pharmacological treatment (Fig. $3 E$ ). Thus, we next examined whether these neurons shared another hallmark of pacemakers, i.e., a positive causal correlation between oscillation frequency and "baseline" $V_{\text {mem }}$ (Crunelli and Hughes, 2010). Similar to intrinsic oscillators described in other circuits (Hayar et al., 2004; Blethyn et al., 2006; Tazerart et al., 2008), oscillation frequency changed as a function of depolarizing or hyperpolarizing current injection in synaptically isolated oscillating $\mathrm{AOB}$ 
A

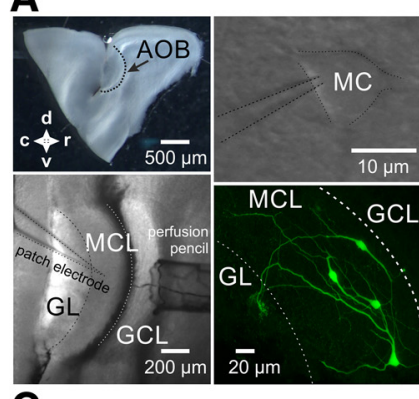

C

(i)

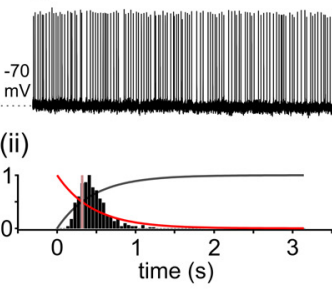

$\mathbf{E}_{(\mathrm{i})}$

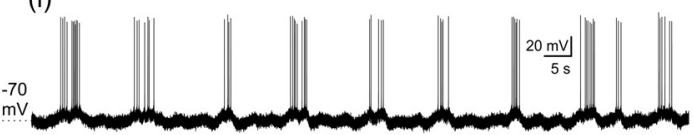

(ii)

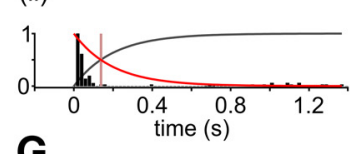

G

(i)

irregular
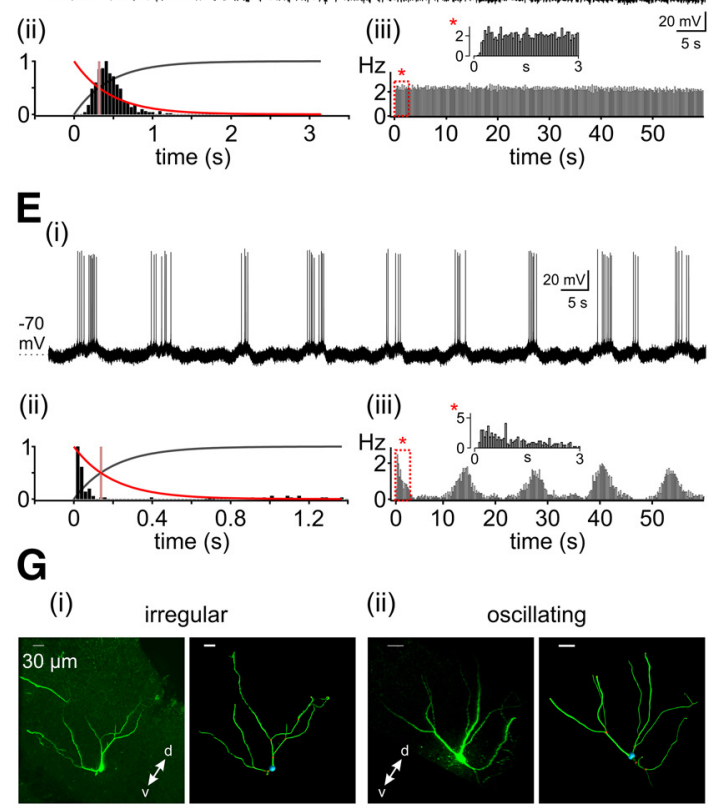

(ii)

oscillating

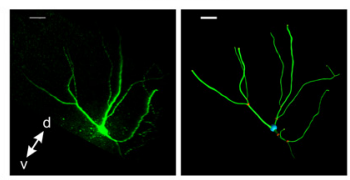

B (i)

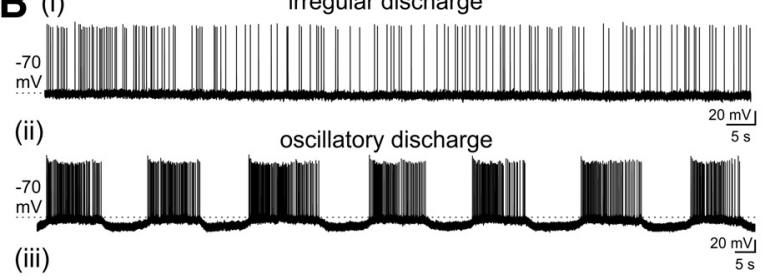

(iii)

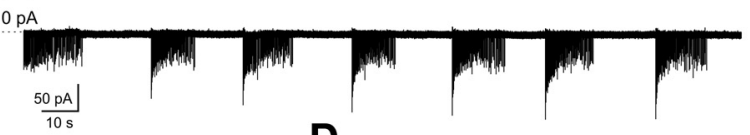

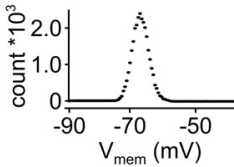

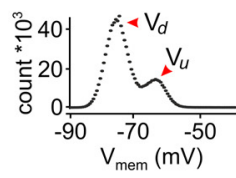

D

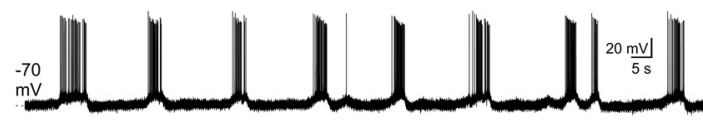

(ii)

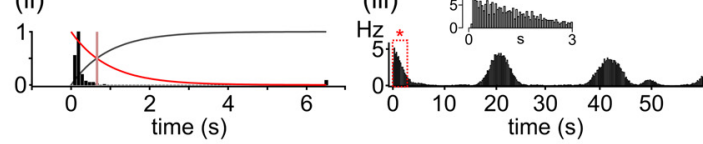

$\mathbf{F}$

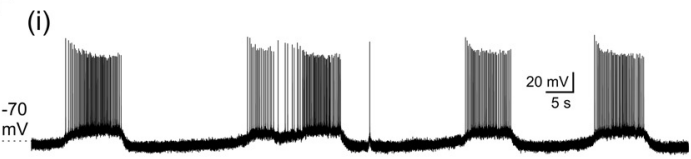

(ii)

(iii)
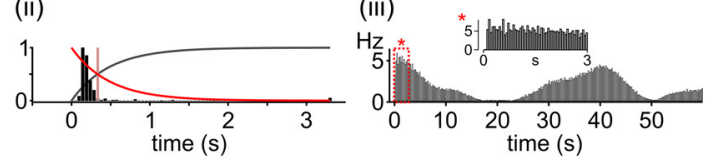

(iii)

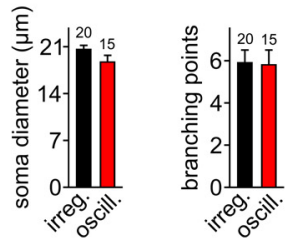

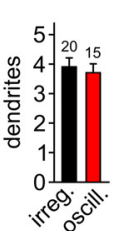

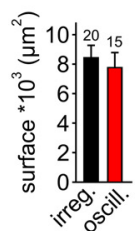

Figure 2. Patterns of spontaneous activity in AOB mitral cells in vitro. $A$, Photomicrographs illustrating the experimental approach. Top, Left, Parasagittal section ( $250 \mu \mathrm{m}$ ) of the mouse rostral brain, including the $A O B$ (dotted line). Bottom, Left, Infrared differential interference contrast image showing the layered structure of the $A O B$ as well as typical experimental configurations of patch electrode and perfusion pencil. Granule cell layer (GCL), glomerular layer (GL), and mitral cell layer (MCL) are indicated. Top, Right, Infrared differential interference contrast photomicrograph showing a region of the MCL at higher magnification. Dotted lines indicate the patch pipette targeting a mitral cell (MC) soma. Bottom, Right, Maximum projection of a confocal $z$-stack illustrates four MCs that were loaded with Alexa Fluor 488 during patch-clamp recordings (see Materials and Methods). $\boldsymbol{B}$, Representative whole-cell current-clamp recordings $\left(S_{2} / S_{5} ; n\right.$ pharmacological perturbation of network activity) illustrating the two distinct types of spontaneous discharge. Mitral cells either fire irregularly (Bi), or exhibit oscillatory discharge patterns (Bii). Rhythmicity (or the lack thereof) is also evident from either one or two peaks in the corresponding $V_{\text {mem }}$ all-points histograms (right). Prominent oscillations are also observed in extracellular loose-seal recordings (Biii). C, Original representative trace (Ci), ISI distribution (Cii), and autocorrelation (Ciii) histogram of an irregularly firing MC. In the ISI histogram (Cii), the gray curve depicts the cumulative probability function and the light red vertical line illustrates the interval corresponding to a cumulative probability of $0.5\left(\mathrm{ISI}_{0.5}\right)$. The red exponential curve represents the "theoretical" stochastic ISI distribution of a Poissonian spike train with a uniform interval probability of $\mathrm{SI}_{0.5}$. Both the uniform shape of the $\mathrm{ACH}$ [200 ms bin width (Ciii)] and the lack of a peak near zero indicate irregular nonbursting firing. Inset, Autocorrelogram (3 s duration, $50 \mathrm{~ms}$ bin width) confirming the lack of a narrow initial peak. Red asterisk ${ }^{*}$ ) and box denote the time window displayed at an enlarged time scale. $\mathbf{D}-\boldsymbol{F}$, Representative original recordings (Di, Ei, Fi), ISI histograms (Dii, Eii, Fii) and autocorrelograms (Diii, Eiii, Fiii) of MC oscillatory discharge reveal distinct types of autorhythmicity. Cumulative ISI probability curve, ISI $\left.\right|_{0.5}$, and Poisson-type ISI curve are derived as in Cii. Regularity of bursting and its diversity is mirrored by the shape of the autocorrelograms (Diii, Eiii, Fiii) with a narrow initial peak close to zero and several "side" peaks (vs the peak-less autocorrelogram indicative of irregular firing in $C$ ). Red asterisks $\left({ }^{*}\right.$ ) and dashed boxes correspond to the initial $3 \mathrm{~s}$ time segments of the autocorrelograms that are displayed at an enlarged scale ( $50 \mathrm{~ms}$ bin width; insets). $\mathbf{G}$, Representative confocal $z$-stack images (1.14 $\mu \mathrm{m}$ intervals; maximum intensity projection) and volumerendered 3D reconstructions of an irregularly firing $(\boldsymbol{G i})$ and an oscillating (Gii) $M C$, respectively. Reconstructed somata are depicted in cyan; dendrites are shown in green. Morphometric analysis (Giii) included soma diameter [20.6 $\pm 0.6 \mu \mathrm{m}$ (irregular) vs $18.7 \pm 1.0 \mu \mathrm{m}$ (oscillatory)], numbers of branching points [5.9 \pm 0.6 (irregular) vs $5.8 \pm 0.7$ (oscillatory)], and dendrites [3.9 \pm 0.3 (irregular) vs $3.7 \pm 0.3$ (oscillatory)], as well as total surface [ $8503 \pm 847 \mu \mathrm{m}^{2}$ (irregular) vs $7828 \pm 1028 \mu \mathrm{m}^{2}$ (oscillatory)]. Bar graphs show means \pm SEM. Numbers of MCs are indicated above bars. Morphological parameters are independent of discharge type ( $p>0.05$; unpaired $t$ test).

mitral cells (Fig. $3 F-H)$. Hyperpolarization increased, whereas depolarization reduced IBIs (Fig. $3 F, H i$ ). Moreover, each neuron (nine of nine cells) exhibited a characteristic $V_{\text {mem }}$ threshold below which the pattern of periodically recurring up and down states switched to a stable resting state (Fig. $3 F, G$ ). Notably, within the voltage range from rest to firing threshold, neither positive nor negative current injections changed a given neuron's general discharge type (i.e., from oscillatory to irregular or vice versa; $n=10$; Fig. 3Fii). Together, these results suggest that the mouse AOB contains a group of intrinsically rhythmogenic mitral cells that generate slow $V_{\text {mem }}$ oscillations independent of fast synaptic input. 


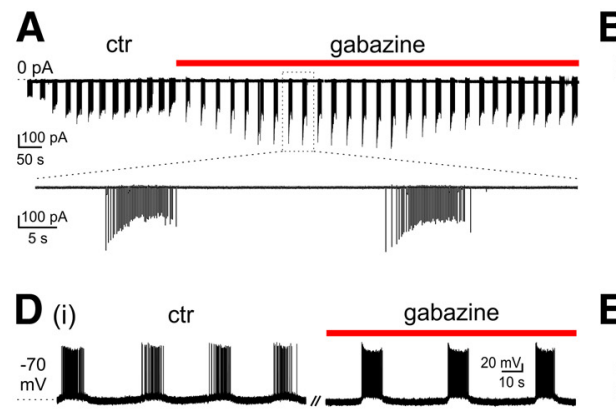

(ii)

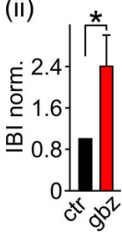

$\mathbf{F}_{(\mathrm{i})}$
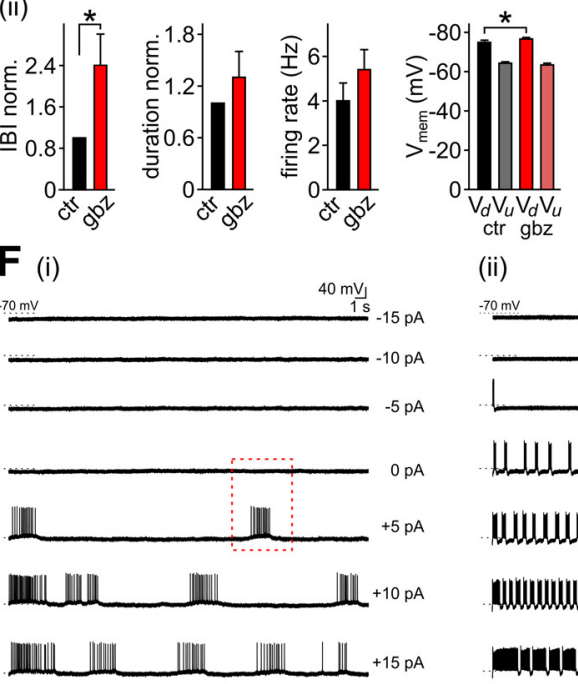

(ii)
B

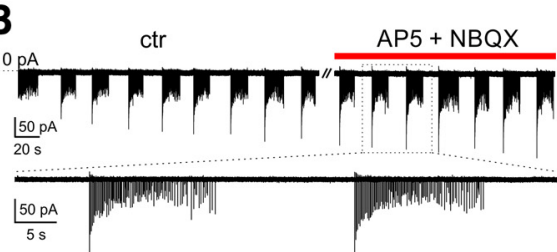

E

(ii)

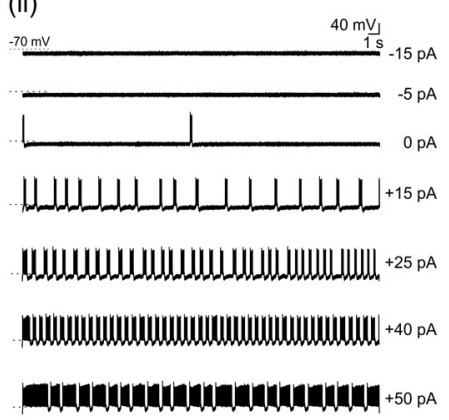

ctr gabazine + AP5 + NBQX
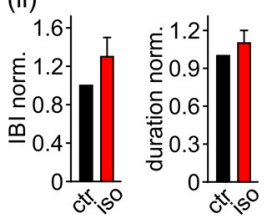
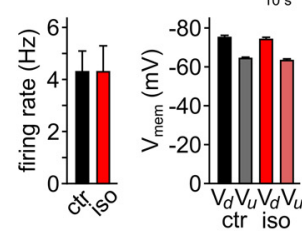

G (i)
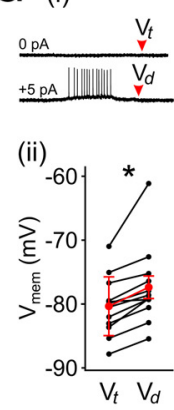

C (i)

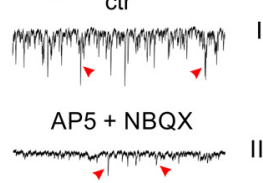

gabazine

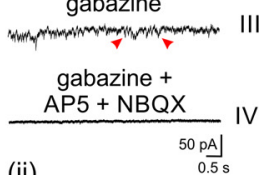

(ii)

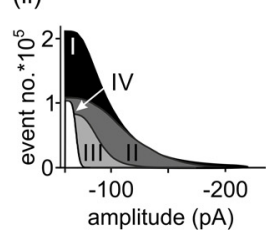

$\mathbf{H}(1)$
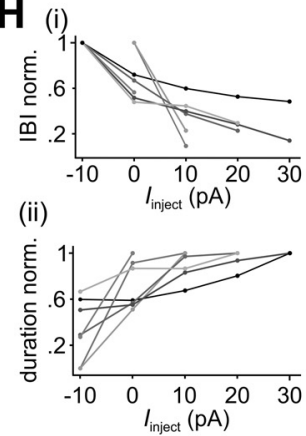

Figure 3. Rhythmic discharge of $A O B$ mitral cells. $A, B$, Extracellular loose-seal recordings from two oscillating mitral cells under control conditions as well as during inhibition of either $G A B A$ ergic $[\boldsymbol{A} ;$ gabazine $(10 \mu \mathrm{m})]$ or glutamatergic $[\boldsymbol{B} ; \mathrm{AP5}(100 \mu \mathrm{M})+\mathrm{NBQX}(10 \mu \mathrm{m})]$ fast synaptic transmission, respectively. Horizontal red bars indicate drug incubation. Bottom traces, Expanded view of two consecutive bursts during either pharmacological treatment. Ci, Original whole-cell recordings $\left(V_{\text {hold }}=-65 \mathrm{mV} ; \mathrm{S}_{2} / \mathrm{S}_{6} ; E_{\mathrm{Cl}}=\sim 0 \mathrm{mV}\right.$ ) of spontaneous postsynaptic currents (spPSCs). Traces exemplify spPSCs as downward deflections of varying amplitudes under control conditions (l; red arrowheads indicate relatively large events). Moreover, recordings show the effects of inhibiting ionotropic glutamate receptors [ll; AP5 $(100 \mu \mathrm{M})+\mathrm{NBQX}(10 \mu \mathrm{m})], \mathrm{GABA}_{\mathrm{A}}$ receptors [III; gabazine $(10 \mu \mathrm{m})$ ], and fast synaptic transmission in general (IV; gabazine + AP5 + NBQX; drug preincubation, $\geq 10$ s). Cii, A histogram of spPSC amplitude distribution illustrates that both AP5/NBQX (II) and gabazine (III) reduce spPSC amplitude and frequency. In combination, the three drugs block essentially all remaining spPSCS (IV). Di, Ei, Representative $V_{\text {mem }}$ recordings from two mitral cells under control conditions as well as during either inhibition of GABA receptors $[\mathbf{D}$; gabazine $(10 \mu \mathrm{M})]$ or a complete block of fast synaptic transmission [E; gabazine $(10 \mu \mathrm{M})+\mathrm{AP5}(100 \mu \mathrm{m})+\mathrm{NBQX}(10 \mu \mathrm{m})]$. Note that oscillatory discharge persists when this mitral cell is isolated from both excitatory and inhibitory synaptic input. Horizontal red bars indicate drug incubation. Dii, Eii, Bar charts comparing oscillatory discharge parameters from rhythmogenic AOB mitral cells under control conditions (ctr; black) versus inhibition of synaptic transmission (red; gabazine, $n=18$; synaptic isolation (iso) by gabazine + AP5 + NBQX, $n=12$ ). Both normalized IBIs and burst durations as well as within-burst firing rates and membrane up and down states $\left(V_{\mathrm{d}} / V_{\mathrm{u}}\right)$ are plotted as means \pm SEM. Block of GABAergic fast synaptic input prolonged IBIs (2.4-fold; \pm 0.6$)$ and hyperpolarized the down state $(-74.9 \pm 1.1 \mathrm{vs}-76.6 \pm 0.8 \mathrm{mV})$. Asterisks $\left(^{*}\right)$ denote statistical significance, $p<0.01$ (Wilcoxon signed-rank test). By contrast, burst durations (1.3-fold; \pm 0.3$)$, within-burst firing frequencies $(4.0 \pm 0.8 \mathrm{vs} 5.4 \pm 0.9 \mathrm{~Hz})$, and up-state potentials $(-64.3 \pm 0.7 \mathrm{vs}-63.4 \pm 0.9 \mathrm{mV}$ ) were essentially unaltered. Moreover, no parameter was changed in absence of synaptic drive ( $p>0.05$; Wilcoxon signed-rank test): IBls, 1.3 -fold; $\pm 0.2 \mathrm{~s}$; burst durations, 1.1 -fold; $\pm 0.1 \mathrm{~s}$; firing frequencies, $4.3 \pm 0.8 \mathrm{vs} 4.3 \pm 1.0 \mathrm{~Hz} ; \mathrm{V}_{\mathrm{d}},-75.1 \pm 1.1 \mathrm{vs}-74.1 \pm 1.1$ $\mathrm{mV} ; \mathrm{V}_{\mathrm{u}} ;-64.3 \pm 0.7 \mathrm{vs}-63.9 \pm 0.9 \mathrm{mV}$. $\boldsymbol{F}$, Original whole-cell current-clamp recordings from two representative oscillating AOB mitral cells during continuous depolarizing or hyperpolarizing current injections of variable amplitude [-15 to $15 \mathrm{pA}(\boldsymbol{F i}) / 50 \mathrm{pA}$ (Fii)]. Gi, Expanded view of the current-clamp recordings shown in $\boldsymbol{F i}$ (dashed red rectangle) illustrating the "switch" from a stable $V_{\text {mem }}$ state (top trace) to slow periodic bursting (bottom trace). Red arrowheads indicate the (sub)threshold $\left(V_{\mathrm{t}}\right)$ and down-state $\left(V_{\mathrm{d}}\right) V_{\text {mem }}$ values, respectively, for this particular mitral cell. Gii, Quantification of $V_{\mathrm{t}}$ versus $V_{\mathrm{d}}$ values. Data points correspond to baseline $V_{\text {mem }}$ measurements in absence $\left(V_{\mathrm{t}}\right)$ and presence $\left(V_{\mathrm{d}}\right)$ of oscillating discharge, respectively. Data from individual mitral cells are connected by black lines $(n=10)$. Compared with $V_{d}(-77.4 \pm 1.8 \mathrm{mV})$, average $V_{t}(-80.3 \pm 1.3 \mathrm{mV})$ is significantly more hyperpolarized (means $\pm S E M$; red), indicating that the mechanisms underlying oscillatory discharge operate in a $V_{\text {mem }}$ range more positive than $-80 \mathrm{mV}$. Asterisk $\left(^{*}\right)$ denotes statistical significance; $p<0.0001$ (paired-sample t test). $\boldsymbol{H i}, \mathbf{H i i}$, Negative (Hi) and positive (Hii) correlation of current injection amplitude with IBIs and burst durations, respectively $(n=7)$. Data are normalized to individual maxima.

Pattern variability among intrinsically oscillating mitral cells Since pacemaker-like neurons can exert profound effects on coding and computation in sensory systems (Izhikevich et al., 2003; Mizuseki et al., 2009), we focused on the subpopulation of intrinsically oscillating AOB mitral cells (iAMCs). Accordingly, we performed subsequent experiments under tonic synaptic inhibition (gabazine, AP5, NBQX). First, we asked whether iAMCs and irregularly discharging neurons differ in their passive membrane properties and/or their spikegeneration machinery. Neither $C_{\text {mem }}$ nor $\tau_{\text {mem }}$ differed significantly (Fig. 4Ai,Aii), suggesting that basic biophysical properties do not distinguish iAMCs from the "general" AOB mitral cell population. $R_{\text {input }}$, however, was slightly increased in iAMCs (Fig. 4Aiii). Comparison of mean instantaneous spike frequencies as a function of stationary current input $(f-I$ curve; 5-100 pA; Fig. 4Aiv) revealed indistinguishable curves for both neuron types with response saturation at amplitudes $>80 \mathrm{pA}$ and maximum average firing frequencies of $\sim 25 \mathrm{~Hz}$. Moreover, averaged spike waveforms from iAMCs and irregularly firing neurons were similar in spike amplitude, duration, and kinetics (Fig. 4Av). Together with the results shown in Figure $2 G$, these data demonstrate that the unique spontaneous activity of iAMCs does not correspond to a readily distinguishable morphological or biophysical phenotype. 
A (i)

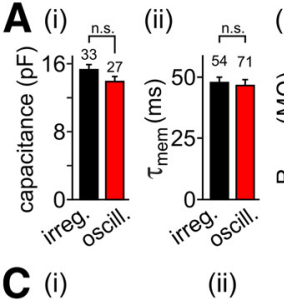

C (i)

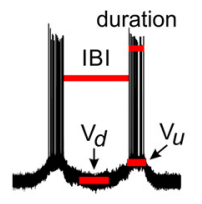

(ii)

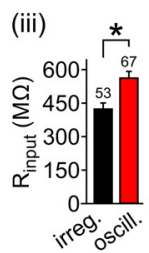

(iv)

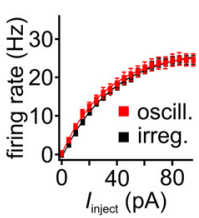

B (i)

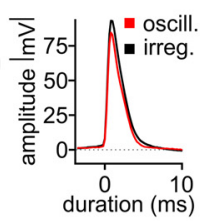

(ii)

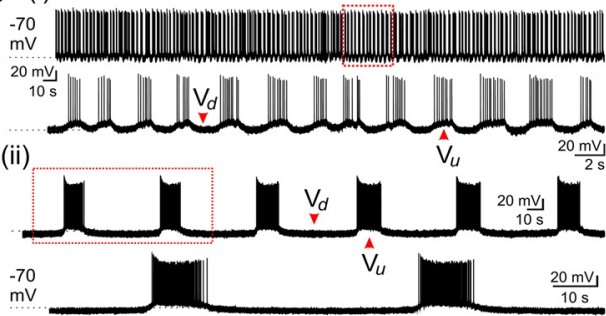

(iii)

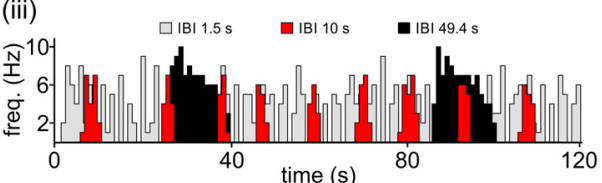

D (i)
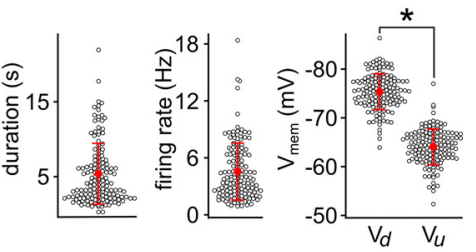

$\mathbf{E}$ (i)

$|B|=13 \mathrm{~s}$

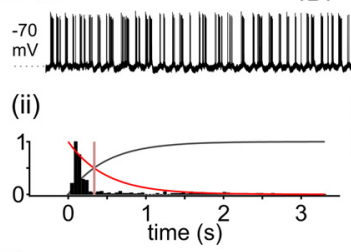

$|\mathrm{B}|=2 \mathrm{~s}$

E (i)
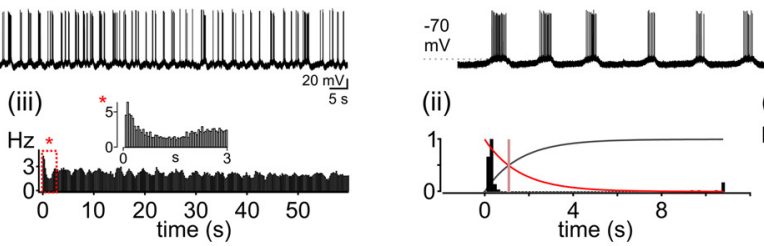

(ii)
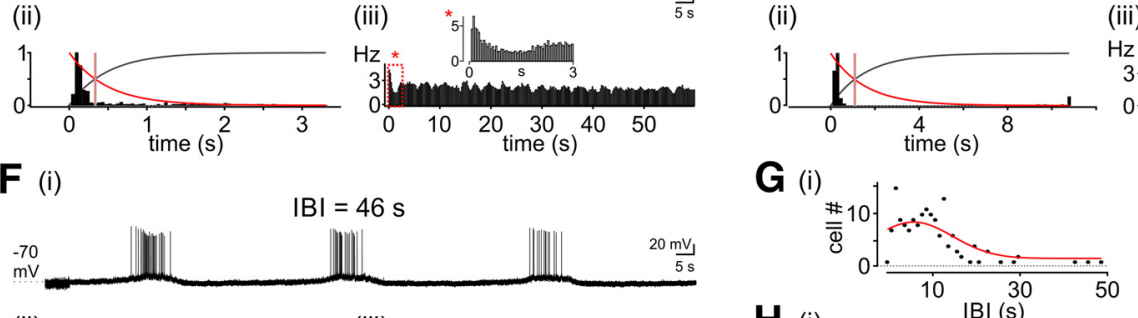

(ii)

(iii)

G (i)

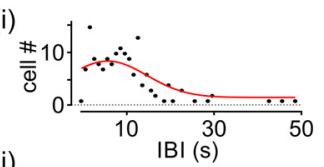

H (i)

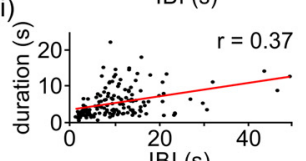

(iii)

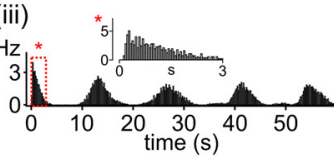

(ii)

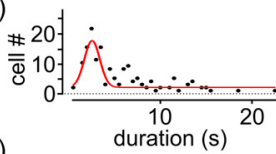

(ii)

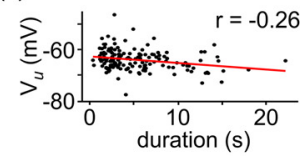

Figure 4. Discharge variability among the iAMC population. Ai-Aiii, Bar charts comparing passive membrane properties of irregularly firing (black) versus intrinsically oscillating (red) AOB mitral cells. Analysis of $C_{\text {mem }}(15.3 \pm 0.6$ vs $13.9 \pm 0.6 \mathrm{pF})$ and time constant $\left(\tau_{\text {mem; }} ; 7.6 \pm 2.2\right.$ vs $\left.46.4 \pm 2.4 \mathrm{~ms}\right)$ reveals no significant (n.s.) differences. By contrast, $R_{\text {input }}$ is significantly increased in iAMCs (560.2 \pm 30 vs $424 \pm 25 \mathrm{M} \Omega$ ). Asterisk (*) denotes statistical significance, $p=0.001$ (Mann-Whitney $U$ test). Data are means \pm SEM. Numbers of experiments are indicated above bars. Aiv, $f-I$ curve depicting average instantaneous discharge frequencies evoked by stationary current injection ( 1 s duration; $5 \mathrm{pA}$ intervals; range, $5-100 \mathrm{pA}$ ) in oscillating (red; $n=24$ ) and irregularly spiking mitral cells (black; $n=30$ ). Maximum frequencies are $24.8 \pm 1.6 \mathrm{~Hz}$ (iAMCs) and $24.5 \pm 1.0 \mathrm{~Hz}$ (irregular), respectively. Individual data points are means \pm SEM. Curves are monoexponential fits. Av, Averaged action potential waveform observed in oscillating (red) versus irregularly spiking (black) mitral cells. Mean traces reveal an average amplitude of $84.6 \mathrm{mV}$ (red) versus 93.1 $\mathrm{mV}$ (black) and a FDHM of $2.2 \mathrm{~ms}$ each. Bi-Biii, Original $V_{\text {mem }}$ recordings (Bi and Bii) and firing rate histograms (Biii) illustrating the heterogeneity of iAMC discharge. Bi, Bii, Bottom traces, Expanded view of the recording period delimited by the dashed rectangles. Red arrowheads indicate $V_{d}$ and $V_{u}$, respectively. Biii, Spontaneous discharge frequency histogram of the two iAMCs shown above [gray; IBI, $1.5 \mathrm{~s}$ (Bi); black; IBI, $49.4 \mathrm{~s}$ (Bii)] and a neuron exhibiting an intermediate average IBI of $10.0 \mathrm{~s}$ (red). C, Quantification of oscillatory discharge parameters. Ci, Current-clamp recording of two consecutive bursts schematically exemplifies the discharge properties subject to analysis (horizontal red lines). Cii, Scatter dot plots of individual measurements (open black circles; $n=148$ ). Average values are shown $\pm S D$ (red): $: B l s, 10.7 \pm 8.1 \mathrm{~s}$ (median, $9.3 \mathrm{~s}$ ); burst durations, $5.4 \pm 4.1 \mathrm{~s}$ (median, $3.9 \mathrm{~s}$ ); within-burst firing rates, $4.6 \pm 3.1 \mathrm{~Hz}$ (median, $3.7 \mathrm{~Hz}$ ); $V_{\mathrm{d}},-76.3 \pm$ $3.8 \mathrm{mV}$ (median, $-76.4 \mathrm{mV}$ ); $V_{u^{\prime}}-64.6 \pm 3.8 \mathrm{mV}$ (median, $-64.7 \mathrm{mV}$ ). Asterisk (*) denotes statistical significance, $p<0.0001$ (Wilcoxon signed-rank test). $\boldsymbol{D}-\boldsymbol{F}$, Representative whole-cell $\left(S_{2}\right.$; $\mathrm{S}_{5}$ ) current-clamp recordings (Di, Ei, Fi), ISI histograms (Dii, Eii, Fii), and autocorrelograms (Diii, Eiii, Fiii) of three intrinsically oscillating neurons. Recordings were performed in isolation from both excitatory and inhibitory fast synaptic drive [gabazine $(10 \mu \mathrm{m})+$ AP5 $(100 \mu \mathrm{m})+\mathrm{NBQX}(10 \mu \mathrm{m})$ ]. Cumulative ISI probability curves, ISI 0.5 values, and Poisson-type ISI curves are derived as described in Figure 2. Regularity is evident in the shape of the autocorrelograms (Diii, Eiii, Fiii). Phenotypic heterogeneity among the iAMC population becomes apparent from the wide distribution of IBIs, which range from $\sim 2 s(\boldsymbol{D})$ to $>45 \mathrm{~s}(\boldsymbol{F})$. Diii, Eiii, Fiii, Insets, ACHs (3 s duration; $50 \mathrm{~ms}$ bin width); red asterisks (*) and dashed boxes denote "expanded" views. Gi, Gii, Distribution of IBls (Gi) and burst durations (Gii) among the iAMC population $[n=148 ; 1 \mathrm{~s}$ (Gi) and $0.5 \mathrm{~s}$ (Gii) bin width, respectively]. While data points preferentially scatter on the lower end of the scale, their distribution is skewed to the right and is thus not well fit by Gaussian equations (red lines). Hi, Hii, Pairwise iAMC correlation analyses of burst durations with IBIs (Hi) and up-state voltage (Hii), respectively ( $n=148)$. Linear regression indicates no obvious correlation of either parameter pair [Pearson's correlation coefficient, $r=0.37(\boldsymbol{H i})$ and $r=-0.26$ (Hii)].

Next, we analyzed discharge variability among the iAMC population. Similar to in vivo observations (Fig. 1I), measures including IBIs, burst durations, and firing rates within a burst varied considerably across neurons and were not normally distributed (Fig. $4 B, C$ ). Silent periods between bursts lasted on average $10.7 \pm 8.1 \mathrm{~s}( \pm \mathrm{SD})$ with individual IBI values ranging from 1.5 to $49.3 \mathrm{~s}$ (Fig. $4 B-F$ ). Moreover, we observed bursts as brief as $0.3 \mathrm{~s}$, but also prolonged firing periods of $\leq 22.2 \mathrm{~s}$ (average burst duration, $5.4 \pm 3.9 \mathrm{~s}$; mean $\pm \mathrm{SD}$; Fig. $4 B-F)$. Increasing the bath solution's temperature from $25^{\circ} \mathrm{C}$ (RT) to $37^{\circ} \mathrm{C}$ decreased both IBIs and burst duration $(n=3$; data not shown). Distribution analysis of both IBIs and burst durations, however, revealed no obviously segregated sub- populations among iAMCs (Fig. $4 G$ ). The vast majority of iAMCs $(99.4 \%)$ fire $>5$ spikes per burst, translating into an average within-burst firing rate of $4.6 \pm 3.0 \mathrm{~Hz}$ (mean $\pm \mathrm{SD}$; range, $0.9-18.6 \mathrm{~Hz}$ ). Notably, the average voltage change during transitions from down to up states is $11.5 \mathrm{mV}(-76.1 \pm 3.9$ to $-64.6 \pm 4.0 \mathrm{mV}$; means $\pm \mathrm{SD}$ ), indicating that any current(s) providing the excitatory drive to iAMCs must operate within this voltage regime. To examine whether oscillation parameters are interdependent, we carried out pairwise correlation analyses of IBIs, burst durations, and up-state voltage $\left(V_{\mathrm{u}}\right)$, respectively (Fig. $\left.4 H\right)$. Our results, however, indicate no obvious correlation between any parameter pair, suggesting that the antagonistic mechanisms underlying the recurring 
transition and maintenance of depolarization and hyperpolarization are phenotypically independent.

Together, these findings show that iAMCs are a physiologically distinct subgroup of AOB mitral cells that share pacemaker-like discharge properties, spanning a wide range of mechanistically independent characteristics within the oscillation parameter space.

\section{$I_{\mathrm{NaP}}$ promotes rhythmogenesis}

The cyclical interplay of depolarizing and hyperpolarizing pacemaker currents drives autorhythmicity and burst generation in a variety of neurons (Grillner, 2006; Blankenship and Feller, 2010). Conceptually, these currents provide either the transitional excitatory drive from down to up state, the translation into a regular firing pattern during the up-state plateau, or the hyperpolarization that terminates the burst (Colwell, 2011). The hyperpolarization-activated current $\left(I_{\mathrm{h}}\right)$, the low-voltage-activated T-type $\mathrm{Ca}^{2+}$ current $\left(I_{\mathrm{T}}\right)$ and $I_{\mathrm{NaP}}$ are prototypical depolarizing pacemaker currents and, thus, major determinants of autorhythmicity (Crill, 1996; Perez-Reyes et al., 1998; Chan et al., 2004). $I_{\mathrm{h}}$, in particular, is a predominant driving force of rhythmic oscillatory activity (Maccaferri and McBain, 1996; Liu and Shipley, 2008). Therefore, we tested whether $I_{\mathrm{h}}$ is involved in oscillatory iAMC discharge. The bradycardic agent ZD7288, a specific but isoformindependent blocker of hyperpolarization-activated cyclic nucleotide-gated channels (BoSmith et al., 1993), did not alter iAMC rhythmic activity (Fig. $5 A, B$ ). $I_{\mathrm{h}}$ expression typically manifests as a rebound depolarization (sag) at hyperpolarized potentials (Cichy et al., 2015). In current-clamp recordings, we thus measured the hyperpolarization-evoked sag potential in iAMCs under control conditions (Fig. 5C). Plotting the sag potential amplitude as a function of peak hyperpolarization (Fig. 5D) revealed that pronounced voltage sags were only detected upon membrane hyperpolarization to values substantially more negative than the average down-state potential $\left(V_{\mathrm{d}}\right)$. Thus, these results indicate that $I_{\mathrm{h}}$ serves a minor, if any, role in iAMC rhythmogenesis.

Another common subthreshold current that is frequently involved in $V_{\text {mem }}$ bistability and burst generation is $I_{\mathrm{T}}$ (Bean, 2007; Crunelli and Hughes, 2010). Especially in neurons characterized by relatively hyperpolarized $V_{\text {rest }}$, these lowthreshold currents frequently accelerate
A

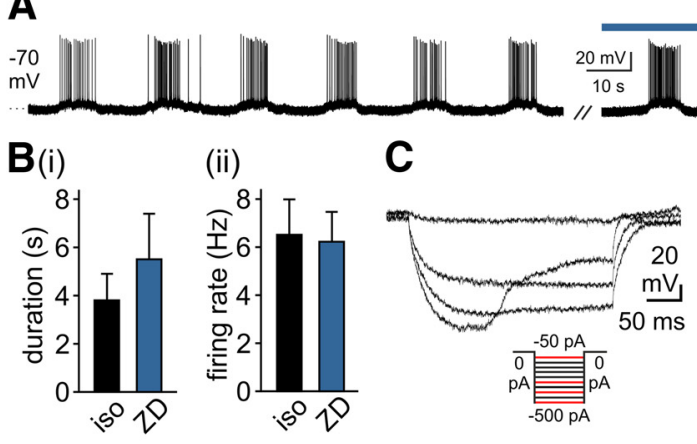

$40 \mu \mathrm{M}$ ZD7288

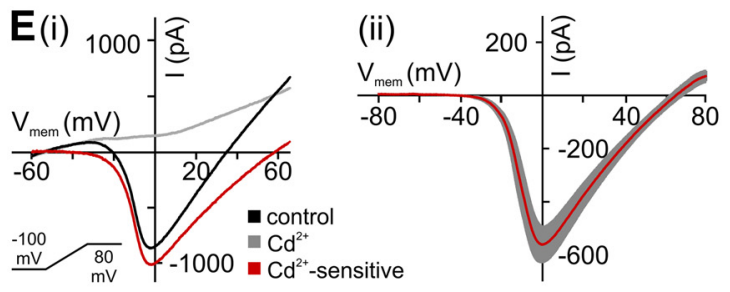

D

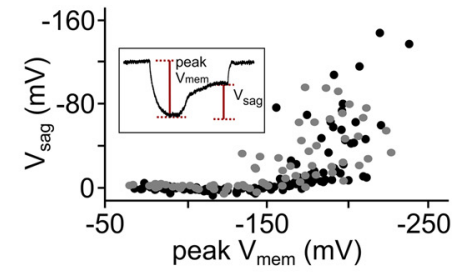

$\mathbf{F}(\mathrm{i})$

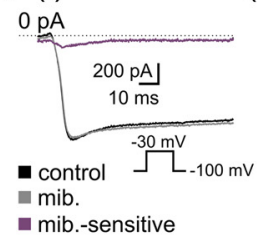

(ii)

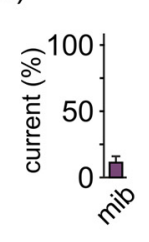

G (i)

$10 \mu \mathrm{M}$ mibefradil

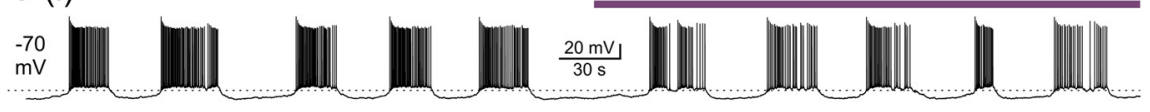

(ii)
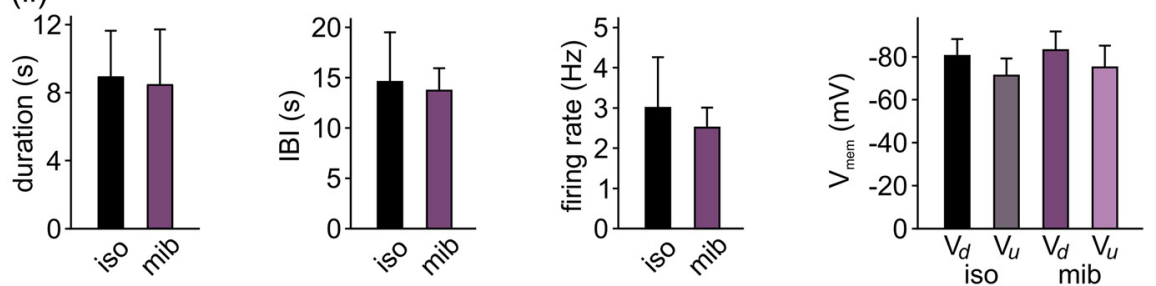

Figure 5. $I_{\mathrm{h}}$ and $I_{\mathrm{T}}$ serve minor roles in $\mathrm{AMMC}$ autorhythmicity. $A$, Representative whole-cell current-clamp recording of oscillatory iAMC discharge before (left) and during (right) ZD7288 treatment ( $40 \mu \mathrm{m}$; horizontal blue bar; preincubation, $\geq 3 \mathrm{~min}$ ). Drug efficacy was confirmed in parallel recordings from vomeronasal sensory neurons (Cichy et al., 2015). B, Bar charts comparing iAMC discharge ( $n=12$ ) under synaptically isolated conditions (iso; black) versus ZD7288-dependent hyperpolarization-activated cyclic nucleotide-gated channel inhibition (ZD; blue). Bi, Bii, Burst durations (Bi) and firing rates $(\boldsymbol{B i i})$ are plotted as means \pm SEM. Both parameters are essentially unaffected by ZD7288 treatment $(p>0.05$; paired sample $t$ test): burst durations ( $3.8 \pm 1.1 \mathrm{~s}$ vs $5.5 \pm 2.0 \mathrm{~s})$; burst firing frequencies $(6.5 \pm 1.5 \mathrm{vs} 6.2 \pm 1.3 \mathrm{~Hz})$. $C$, Representative whole-cell current-clamp recordings in response to hyperpolarizing current injections ( -50 to $-500 \mathrm{pA}$; $-50 \mathrm{pA}$ increments; $300 \mathrm{~ms}$ duration). Exemplary original traces of $V_{\text {mem }}$ hyperpolarizations evoked by $-50,-300$, -400 , and $-500 \mathrm{pA}$ (red lines in pulse protocol; inset) demonstrate the voltage dependence of the sag potential $\left(V_{\text {sag }}\right)$ amplitude. No sag was observed in presence of ZD7288 (data not shown). D, Scatter plot depicting the relationship between $V_{\text {sag }}$ and peak hyperpolarization. For quantification, $V_{\text {sag }}$ is determined as the voltage difference between the peak hyperpolarization and the steady-state $V_{\text {mem }}$ (inset). Data points correspond to intrinsically oscillating (gray) and irregularly firing (black) mitral cells $(n=12)$. Note that considerable hyperpolarization $(\leq-130 \mathrm{mV})$ is required to elicit rebound depolarization. $\boldsymbol{E i}$, Representative recordings of $I-V$ relationships as determined by fast ascending voltage ramps (inset: -100 to $+80 \mathrm{mV}, 100 \mathrm{~ms}$ duration; $V_{\text {mem }}$ range shown, -60 to $65 \mathrm{mV}$ ) in absence (black) and presence (gray) of $\mathrm{Cd}^{2+}(200 \mu \mathrm{M})$. The red trace depicts the difference between $I-V$ plots under control conditions and during $\mathrm{Cd}^{2+}$ incubation and thus corresponds to the $\mathrm{Cd}^{2+}$-sensitive $\mathrm{Ca}^{2+}$ current. Eiii, Average $\mathrm{I}-V$ relationship of $\mathrm{Cd}^{2+}$-sensitive $\mathrm{Ca}^{2+}$ currents (red trace; $\left.n=18\right)$. Gray "shadow" represents SEM. Peak currents are detected at $\sim 0 \mathrm{mV}(-563 \pm 66 \mathrm{pA})$. $\mathbf{F i}$, Representative recordings in response to step depolarization (from -100 to $-30 \mathrm{mV}$; inset) in absence (black) and presence (gray) of mibefradil $(10 \mu \mathrm{m})$. Negligible mibefradil-sensitive current is isolated by digital subtraction (violet trace). Fii, Quantification of fractional mibefradil-sensitive current density. When normalized to total peak current, mibefradil treatment blocked $11.2 \pm 4.8 \%$ (mean $\pm \mathrm{SEM} ; n=4$ ) of inward current. Gi, Representative whole-cell currentclamp recording of oscillatory iAMC discharge before (left) and during (right) mibefradil treatment (10 $\mu \mathrm{m}$; horizontal violet bar). Gii, Bar diagrams comparing iAMC discharge parameters $(n=4)$ under synaptically isolated control conditions (iso; black) versus mibefradil treatment (mib; violet). Burst duration, IBI, firing rate, and $V_{\text {mem }}$ values are shown before (black) and during mibefradil incubation (violet). Data are plotted as means \pm SD. All parameters are essentially unaffected by mibefradil ( $p>0.05$; paired sample $t$ test): burst durations, $8.9 \pm 2.7$ versus $8.5 \pm 3.3 \mathrm{~s}$; IBIs, $14.6 \pm 4.9$ versus $13.7 \pm 2.2 \mathrm{~s}$; burst firing frequencies, $3.0 \pm 1.3$ versus $2.5 \pm 0.5 \mathrm{~Hz} ; V_{\text {mem }}: V_{d}=-80.5 \pm 7.7$ versus $-83.2 \pm 8.8 \mathrm{mV}$; $V_{\mathrm{u}}=-71.4 \pm 7.9$ versus $-75.2 \pm 10.0 \mathrm{mV}$. 


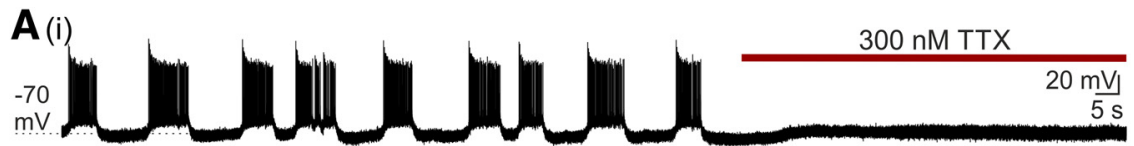

(ii)

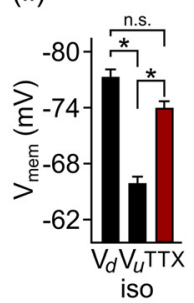

(iii)

(iv)

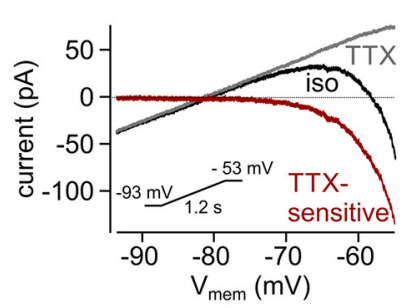

$\mathbf{B}$ (i)

$0.1 \mathrm{mM} \mathrm{Ca}^{2+}$

mv

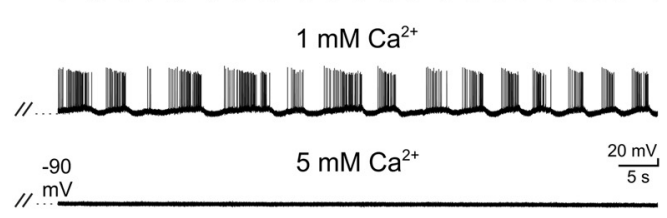

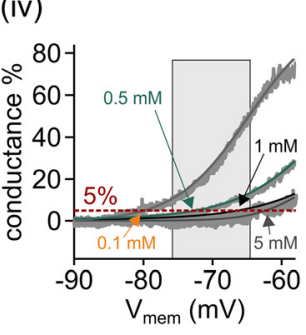

(ii)

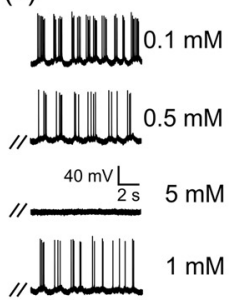

Figure 6. $I_{\text {Nap }}$ is a major determinant of iAMC autorhythmicity. Ai, Representative whole-cell current-clamp recording under isolation from fast synaptic input (gabazine + AP5 + NBQX) in absence and presence of TTX ( $300 \mathrm{~nm}$; horizontal red bar). Aii, Bar diagram quantifying average $V_{\text {mem }}$ values $(n=13)$ before (black; $\left.V_{d}=-77.2 \pm 0.9 \mathrm{mV} ; V_{u}=-65.8 \pm 0.8 \mathrm{mV}\right)$ and after TTX incubation (red; $-73.5 \pm 0.8 \mathrm{mV}$ ). Data are means \pm SEM. Asterisks $(*$ ) denote statistical significance, $p<0.0001$ (KruskalWallis test); n.s., not significantly different. Aiii, Isolation of Nap $_{\text {: }}$ representative $/$-V relationships of average whole-cell currents (3 consecutive recordings) evoked by a slow $(10 \mathrm{mV} / 300 \mathrm{~ms}$ ) ascending voltage ramp from -93 to $-53 \mathrm{mV}$ (inset) in absence (black trace) and presence (gray trace) of TTX ( $300 \mathrm{~nm}$ ). When data recorded during drug treatment were digitally subtracted from control recordings and plotted as a function of the command voltage, the TTX-sensitive negative slope current becomes apparent (red trace). Note the TTX-insensitive linear leak current. Aiv, At different $\left[\mathrm{Ca}^{2+}\right]_{\mathrm{ex}}$ TTX-sensitive currents (revealed by off-line subtraction) were converted to conductances and normalized quasi-steady-state activation curves were fit by the Boltzmann equation $\left(0.1 \mathrm{~mm} \mathrm{Ca}^{2+}\right)$ or extrapolated from monoexponential functions (solid lines on top of shaded traces). Dashed horizontal red line denotes a $5 \%$ conductance threshold. The gray rectangle indicates the "oscillatory" $V_{\text {mem }}$ range delimited by average $V_{d}$ and $V_{u}$ values (Fig. 4 Cii). $A \boldsymbol{v}$, Bar chart depicting $V_{\text {mem }}$ values ( $n=7$; means $\pm S E M$ ) that correspond to $5 \%$ activation of persistent $\mathrm{Na}^{+}$ conductance. Data are plotted as a function of $\left[\mathrm{Ca}^{2+}\right]_{\mathrm{ex}}:-80.2 \pm 0.4 \mathrm{mV}$ (0.1 mм; orange); $-73.4 \pm 2.4 \mathrm{mV}$ (0.5 mm; green); $-70.3 \pm 2.2 \mathrm{mV}\left(1 \mathrm{~mm}\right.$; black); $-65.2 \pm 2.2 \mathrm{mV}\left(5 \mathrm{~mm}\right.$; gray). Asterisks $\left({ }^{*}\right)$ denote statistical significance, $p<0.05$ (one-way ANOVA with Tukey's HSD post hoc test). Bi, Bii, Original whole-cell current-clamp recordings from two representative iAMCs at different $\left[\mathrm{Ca}^{2+}\right]_{\mathrm{ex}}$ levels (preincubation, $\geq 3 \mathrm{~min}$ ). Bii, Note that oscillations recover after restoration of physiological $\left[\mathrm{Ca}^{2+}\right]_{\mathrm{ex}}$. Biii, Bar diagram illustrating IBIs as a function of $\left[\mathrm{Ca}^{2+}\right]_{\mathrm{ex}}$. Data $(n=5$; means \pm SEM) are normalized to control conditions ( $1 \mathrm{mM}$ $\left(a^{2+}\right)$ : $0.44 \pm 0.15$ (0.1 mm; orange); $0.88 \pm 0.14$ (0.5 mm; green). Asterisk $\left(^{*}\right)$ denotes statistical significance, $p<0.05$ (one-way ANOVA with Tukey's HSD post hoc test).

the down-state-to-up-state transition (Llinás and Yarom, 1986) by providing additional subthreshold depolarizing drive. Thus, we asked whether iAMCs express low-threshold T-type $\mathrm{Ca}^{2+}$ channels. In fast voltage ramp recordings, $\mathrm{Cd}^{2+}$-sensitive $\mathrm{Ca}^{2+}$ currents first manifested at suprathreshold $V_{\text {mem }}(>-40 \mathrm{mV})$ and $I-V$ curves did not display a characteristic "dent" at subthreshold voltages (Fig. 5E). Moreover, $\mathrm{Ca}^{2+}$ currents were essentially insensitive to mibefradil (Fig. $5 F$ ), a drug that preferentially inhibits T-type $\mathrm{Ca}^{2+}$ channels (Martin et al., 2000). Consistent with this observation, rhythmic discharge patterns of oscillating iAMCs remained essentially unchanged upon exposure to mibefradil (Fig. 5G). Thus, our data strongly suggest that iAMCs do not display substantial $I_{\mathrm{T}}$.

As a regenerative depolarizing current between $V_{\text {rest }}$ and spike threshold, TTX-sensitive $I_{\mathrm{NaP}}$ affects both firing pattern and frequency (Crill, 1996; Tazerart et al., 2008). Thus, we next examined whether TTX, in addition to disrupting action potential discharge, would also affect subthreshold $V_{\text {mem }}$ oscillations. Indeed, incubation with TTX abolished $V_{\text {mem }}$ fluctuations (Fig. $6 \mathrm{Ai}$ ). In presence of the toxin, iAMCs exhibited stable $V_{\text {mem }}$ val-

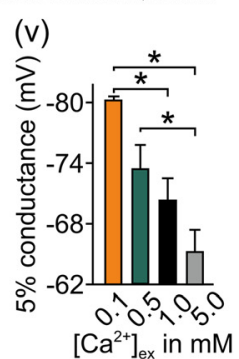

(iii)

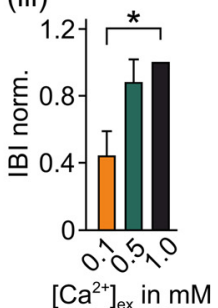

ues that were statistically indistinguishable from $V_{\mathrm{d}}$ (Fig. 6Aii). Since selective pharmacological block of $I_{\mathrm{NaP}}$ has proven difficult (Ramirez et al., 2011; Richter et al., 2014), we evoked and isolated TTXsensitive steady-state currents by slow depolarizing voltage ramps (Carter et al., 2012). A TTX-sensitive current was first evident at $\sim-75 \mathrm{mV}$ and increased steeply with voltage (Fig. 6Aiii). As known for $I_{\mathrm{NaP}}$ (Bean, 2007), maximum steadystate currents were only a small fraction of the maximum $I_{\mathrm{NaT}}(2.2 \% ; n=7$; data not shown). At subthreshold voltages, however, such currents of only tens of picoamperes may prove functionally significant. If so, average $V_{\mathrm{u}}$ and $V_{\mathrm{d}}$ values must be within the voltage-operating range of $I_{\mathrm{NaP}}$, which is indeed the case (Fig. 6Aiv).

A shift in voltage dependence caused by changes in extracellular $\mathrm{Ca}^{2+}$ concentration $\left(\left[\mathrm{Ca}^{2+}\right]_{\mathrm{ex}}\right)$ is another hallmark of $I_{\mathrm{NaP}}$ (Su et al., 2001). Thus, we tested whether activation of TTXsensitive steady-state currents was altered by changes in $\left[\mathrm{Ca}^{2+}\right]_{\mathrm{ex}}$ (Fig. $6 A i v, A v)$. Likely as a result of surface charge screening (Hille, 2001), increasing $\left[\mathrm{Ca}^{2+}\right]_{\mathrm{ex}}$ indeed shifted $I_{\mathrm{NaP}}$ activation to more depolarized values. When converted to conductances and fit by a Boltzmann function (Fig. 6 Aiv), $I_{\mathrm{NaP}}$ activation (calculated as $5 \%$ conductance) varied as a function of $\left[\mathrm{Ca}^{2+}\right]_{e x}$, ranging from $-65.2 \pm 2.2 \mathrm{mV}\left(5 \mathrm{mM} \mathrm{Ca}^{2+}\right)$ to $-80.2 \pm 0.4 \mathrm{mV}\left(0.1 \mathrm{~mm} \mathrm{Ca}^{2+}\right.$; Fig. $6 A v)$. Accordingly, if $I_{\mathrm{NaP}}$ is a major determinant of iAMC autorhythmicity, changes in $\left[\mathrm{Ca}^{2+}\right]_{\mathrm{ex}}$ should alter oscillation patterns. Indeed, IBIs progressively decreased with lower $\left[\mathrm{Ca}^{2+}\right]_{\mathrm{ex}}$ levels (Fig. 6Bi-Biii). By contrast, elevated concentrations $\left(5 \mathrm{mM} \mathrm{Ca}^{2+}\right)$ resulted in cessation of oscillations and stable $V_{\text {mem }}$ values (Fig. $6 B i$ ), an effect that was reversible upon restoration of physiological conditions ( $1 \mathrm{mM} \mathrm{Ca}^{2+}$; Fig. 6Bii). Together, we conclude that TTX-sensitive $I_{\mathrm{NaP}}$ is the major excitatory element that drives $V_{\mathrm{d}}-V_{\mathrm{u}}$ transitions in iAMCs.

\section{R-type $\mathrm{Ca}^{2+}$ channels determine iAMC oscillation patterns}

During the up state, distinct ionic conductances translate the subthreshold excitatory drive into regular trains of action potentials (Colwell, 2011). Thus, we next investigated the mechanistic basis of burst firing during the depolarizing envelope of iAMCs. While the predominant role of $I_{\mathrm{NaT}}$ in $\mathrm{AOB}$ mitral cell spike generation is well established (Castro et al., 2007; Smith and Araneda, 2010; Shpak et al., 2012), voltage-gated $\mathrm{Ca}^{2+}\left(\mathrm{Ca}_{\mathrm{V}}\right)$ channels additionally shape various neuronal discharge parameters (Bean, 2007). Using a pharmacological approach, we first characterized the repertoire of high voltage-activated $\mathrm{Ca}^{2+}$ currents expressed in iAMCs. L-type, P-type/Q-type, and N-type $\mathrm{Ca}^{2+}$ currents were isolated using selective dihydropyridine or peptide toxin $\mathrm{Ca}_{\mathrm{V}}$-channel antagonists (McCleskey et al., 1987; 
Bossert and Vater, 1989; Adams et al., 1993). Notably, iAMC autorhythmicity persisted essentially unaltered in the presence of either $\mathrm{Ca}_{\mathrm{V}}$-channel blocker (data not shown). By contrast, addition of SNX-482, a selective R-type $\mathrm{Ca}^{2+}$ channel inhibitor (Bourinet et al., 2001), dramatically altered iAMC oscillations (Fig. $7 A, B)$. While within-burst firing rates remained unchanged, inhibition of R-type $\mathrm{Ca}^{2+}$ currents $\left(I_{\mathrm{R}}\right)$ significantly decreased IBIs and prolonged burst duration (Fig. 7Aii). These results indicate that, while iAMCs express at least one member of each high voltage-activated $\mathrm{Ca}^{2+}$ channel subfamily, only R-type/ $\mathrm{Ca}_{\mathrm{V}} 2.3$ channels play a significant role in orchestrating autonomous iAMC oscillations.

In iAMCs, $V_{\mathrm{u}}$ is below the activation threshold of SNX-482-sensitive $I_{\mathrm{R}}$ $(>-50 \mathrm{mV}$; Fig. $7 B)$. Therefore, action potentials must provide the depolarization required for $I_{\mathrm{R}}$ activation during the up state. Accordingly, we next examined whether action potential amplitude or shape changed upon $I_{\mathrm{R}}$ inhibition (Fig. 7C). Rise time analysis revealed that SNX-482-sensitive currents contribute little to the action potential rising phase (Fig. 7Cii). By contrast, SNX-482 significantly reduced the amplitude and prolonged the FDHM of average iAMC action potentials (Fig. 7Cii). These data indicate that $\mathrm{Ca}_{\mathrm{V}} 2.3$ channels activate near the action potential peak and that $I_{\mathrm{R}}$ is largest during the falling phase when the driving force on $\mathrm{Ca}^{2+}$ increases.
A (i) $100 \mathrm{nM}$ SNX-482

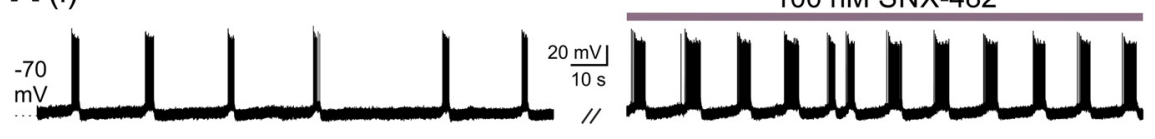

(ii)
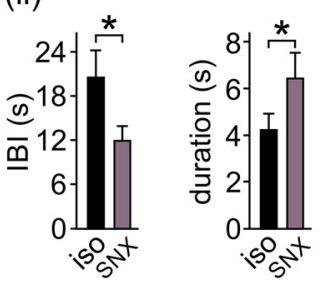

C (i)

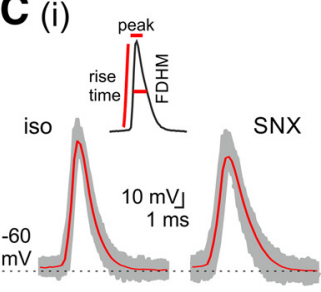

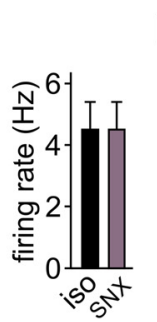

B (i) (ii)

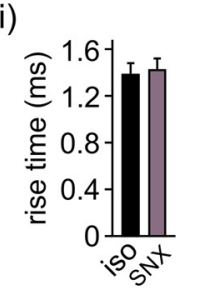

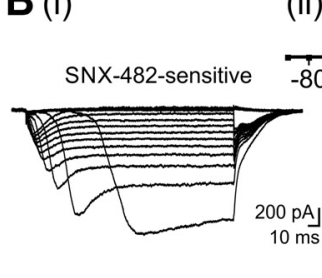

(ii)
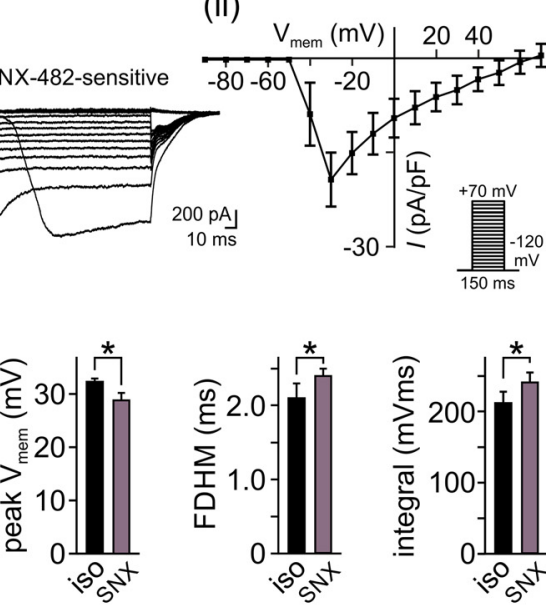

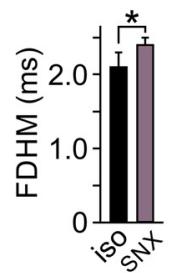

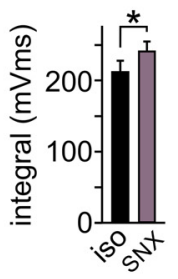

Figure 7. Oscillatory discharge involves R-type Ca channels. $\boldsymbol{A}$, Inhibition of R-type/C $\mathrm{a}_{\mathrm{v}} 2.3$ channels alters iAMC oscillations. Ai, Representative whole-cell current-clamp recording of oscillatory iAMC discharge before (left) and during (right) SNX-482 treatment (100 nm; preincubation, $\geq 3 \mathrm{~min}$ ). Aii, Bar charts comparing iAMC discharge parameters $(n=9)$ under fast synaptic isolation (iso; black) versus additional inhibition of R-type $\mathrm{Ca}_{\mathrm{V}}$ channels (SNX-482; violet). IBls, burst durations, and firing rates are plotted as means \pm SEM. Block of R-type $\mathrm{Ca}^{2+}$ currents shortened IBIs ( $20.5 \pm 3.7 \mathrm{vs} 11.9 \pm 2.0 \mathrm{~s}$ ) and increased burst duration $(4.2 \pm 0.7$ vs $6.4 \pm 1.1 \mathrm{~s})$. By contrast, within-burst firing frequencies $(4.5 \pm 0.9 \mathrm{vs} 4.5 \pm 0.9 \mathrm{~Hz})$ were essentially unaffected. Asterisks $\left({ }^{*}\right)$ denote statistical significance, $p<0.01$ (Wilcoxon signed-rank test). Bi, Bii, Both representative traces from voltage step recordings ( $\mathbf{B i}$; whole-cell; $\mathrm{S}_{4} / \mathrm{S}_{7}$ ) and the corresponding $\mathrm{I}-\mathrm{V}$ curve (Bii) reveal a voltage-dependent slowly inactivating inward current sensitive to SNX-482 (digital off-line subtraction). Steady-state current densities (means \pm SEM; $n=4)$ are plotted as a function of membrane depolarization. Step protocol as indicated. Maximum currents $(-19.3 \pm 4.3 \mathrm{pA} / \mathrm{pF})$ are detected at $-30 \mathrm{mV}$. Ci, Spike waveforms recorded under synaptic isolation (iso; left; $n=131$ ) and in additional presence of SNX-482 (right; $n=493$ ). Recording duration, 180 s. Average action potentials are shown in red; gray shadows indicate SD. Inset, Schematic spike illustrating action potential analysis parameters: rise time, peak $V_{\text {mem}}$, FDHM. Cii, Bar charts comparing characteristic spike parameters in absence (iso; black) and presence (SNX; violet) of SNX-482. Data are means \pm SEM $(n=9)$. While rise time is unchanged ( $1.38 \pm 0.1 \mathrm{vs} 1.42 \pm 0.1 \mathrm{~ms})$, SNX-482 treatment results in reduced peak $V_{\text {mem }}$ values $(32.3 \pm 0.6 \mathrm{vs} 28.8 \pm$ $1.4 \mathrm{mV}$ ) and prolonged repolarization (FDHM: $2.1 \pm 0.2 \mathrm{vs} 2.4 \pm 0.1 \mathrm{~ms}$; integral: $212 \pm 16 \mathrm{vs} 241 \pm 14 \mathrm{mV}^{*} \mathrm{~ms}$ ). Asterisks $\left(^{*}\right)$ denote statistical significance, $p<0.01$ (Wilcoxon signed-rank test).
Big conductance $\mathrm{K}^{+}$channel-dependent negative feedback regulates burst duration

A prolonged action potential FDHM as a result of blocking a $\mathrm{Ca}^{2+}$ inward current (Fig. 7Cii) is somewhat counterintuitive. Apparently, the net effect of blocking $\mathrm{Ca}^{2+}$ entry is to inhibit a net outward current. $\mathrm{Ca}^{2+}$-activated $\mathrm{K}^{+}\left(\mathrm{K}_{\mathrm{Ca}}\right)$ channels are likely mediators of such effects (Bean, 2007). Therefore, we next asked whether $\mathrm{Ca}^{2+}$-activated $\mathrm{K}^{+}$conductances are involved in iAMC oscillations.

Underlying the afterhyperpolarization that follows single spikes or bursts, for example in the hippocampus (Alger and Nicoll, 1980), small conductance $\mathrm{K}_{\mathrm{Ca}}$ (SK) channels are major determinants of firing rate. Thus, we first investigated whether the selective SK channel antagonist apamin (Blatz and Magleby, 1986) affects rhythmic iAMC discharge. Surprisingly, SK channel block did not affect iAMC oscillations (Fig. 8A), consistent with the lack of a substantial apamin-sensitive $\mathrm{K}_{\mathrm{Ca}}$ current in voltageclamp experiments (Fig. 8B).

Other candidates for mediating a $\mathrm{Ca}^{2+}$-activated $\mathrm{K}^{+}$efflux during discharge are big conductance $\mathrm{K}_{\mathrm{Ca}}(\mathrm{BK})$ channels. $\mathrm{BK}$ channels, which are cooperatively activated by depolarization and increased cytoplasmic $\mathrm{Ca}^{2+}$ (Fakler and Adelman, 2008), are inhibited by both TEA and the selective organic blocker paxilline (Brenner et al., 2005). In iAMCs, relatively low TEA concentrations (1 $\mathrm{mm}$ ) reversibly switched oscillatory discharge to irregular tonic firing (Fig. $8 \mathrm{C}$ ), suggesting that coupling of $\mathrm{Ca}^{2+}$ entry to activation and "build up" of $I_{\mathrm{BK}}$ might cause burst termination and, consequently, the following transition to $V_{\mathrm{d}}$ (Crunelli et al., 2012). To quantify the relative contributions of $I_{\mathrm{BK}}$ and $I_{\mathrm{CaV}}$ to pacemaking, we then used an iAMC's own representative burst firing pattern as a voltage command and recorded both TEA-sensitive and $\mathrm{Cd}^{2+}$. sensitive currents (Fig. 8Di). When single spike-dependent currents were plotted as a function of event number (Fig. 8Dii-Div), both putative $I_{\mathrm{BK}}$ and $I_{\mathrm{CaV}}$ monotonically increased and gradually reached saturation after $\sim 15-20$ events. Thus, while the recorded template showed spike-amplitude adaptation, contributions of $\mathrm{BK}$ and $\mathrm{Ca}_{\mathrm{V}}$ channels were largest in later stages of up-state bursting. Moreover, TEA-sensitive and $\mathrm{Cd}^{2+}$-sensitive charge transfer was strongly correlated (Fig. $8 D v$ ). Together, these data suggest that, during prolonged firing, a gradual increase in cytoplasmic $\mathrm{Ca}^{2+}$ is coupled to progressive activation of $\mathrm{BK}$ channels, which ultimately causes burst termination. If so, selective inhibition of $I_{\mathrm{BK}}$ should increase up-state duration and reduce IBIs. Low micromolar concentrations of paxilline indeed caused corresponding changes in iAMC rhythmogenesis (Fig. 8E), supporting the 
A (i)

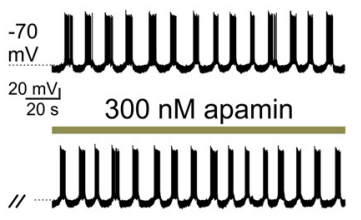

(ii)

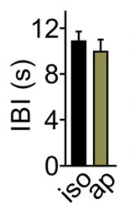

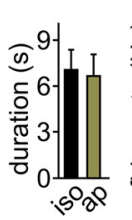

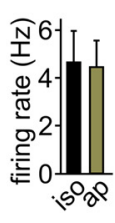

B

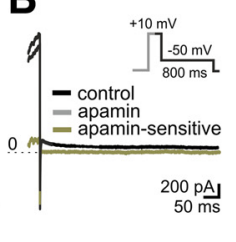

C (i)

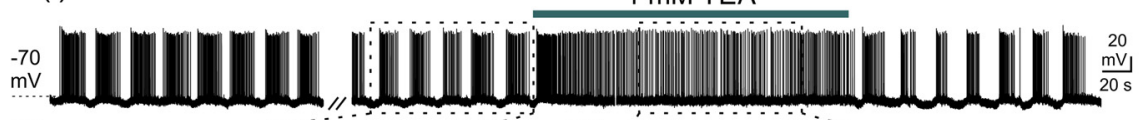

(ii)

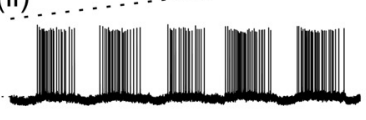

D (i)
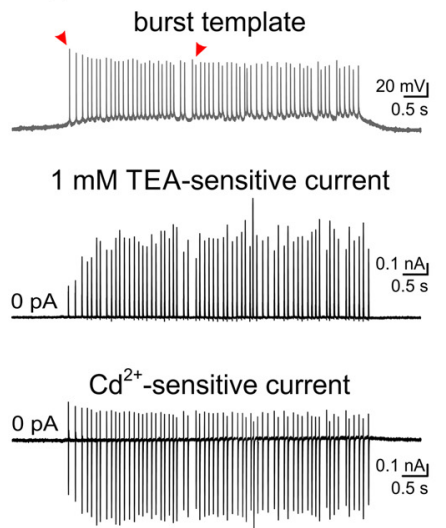

$E$ (i)
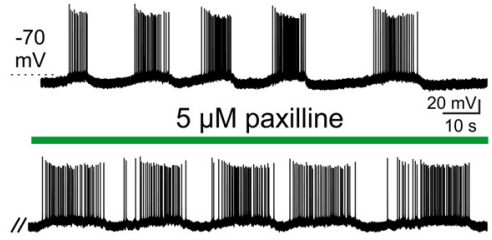

1 mM TEA-sensitive current (iii)

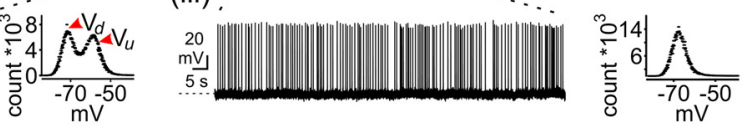

(ii)

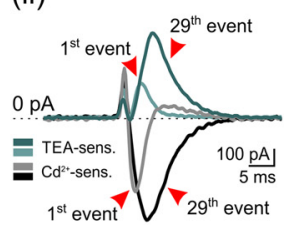

(iii)

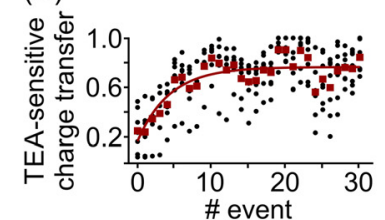

(iv)

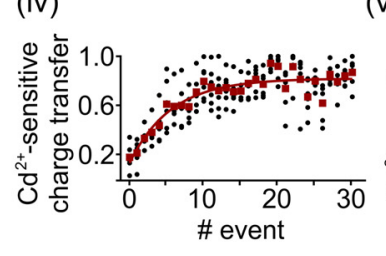

(v) $\bar{s}$

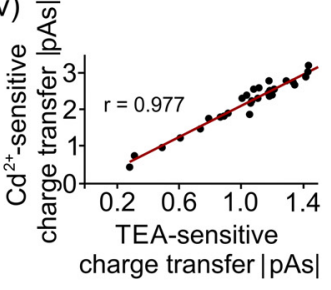

(ii)

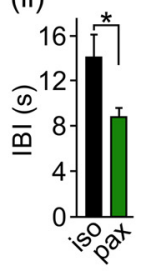

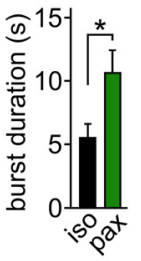

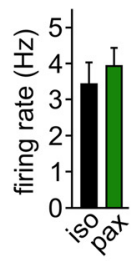

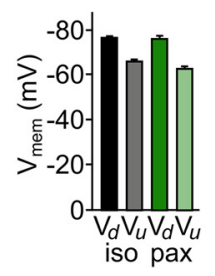

Figure 8. Functional interaction of $\mathrm{C}_{\mathrm{V}}$ and $\mathrm{BK}$ channels determines burst properties. Ai, Representative current-clamp recording of oscillatory discharge before (top) and during (bottom) apamin treatment ( $300 \mathrm{~nm}$; preincubation, $\geq 3 \mathrm{~min}$ ). Aii, Bar charts comparing iAMC discharge parameters $(n=10)$ under control conditions (black) versus inhibition of SK channels (apamin; brown). $I B \mid s$, burst durations, within-burst firing rates, and $V_{\text {mem }}$ state are plotted as means \pm SEM. Apamin treatment shows essentially no effect on either parameter ( $p>0.05$; paired sample $t$ test): IBIs, $10.8 \pm 0.9$ versus $9.9 \pm 1.1 \mathrm{~s}$; burst durations, $7.0 \pm 1.3$ versus $6.6 \pm 1.4$ s; within-burst firing frequencies, $4.6 \pm 1.3$ versus $4.4 \pm 1.1 \mathrm{~Hz} ; \mathrm{V}_{\mathrm{d}^{\prime}}-81.1 \pm 1.1$ versus $-80.0 \pm 0.9 \mathrm{mV} ; \mathrm{V}_{\mathrm{u}^{\prime}}$ $-68.7 \pm 0.6$ versus $-67.8 \pm 0.9 \mathrm{mV}$. B, Representative recording of $\mathrm{Ca}^{2+}$-dependent whole-cell currents from AOB mitral cells in response to a "pseudo" tail current pulse protocol (inset) designed to isolate SK channel-mediated currents: "brief" step depolarization ( $+10 \mathrm{mV}, 100 \mathrm{~ms}$ ) triggers $\mathrm{Ca}^{2+}$ influx via $\mathrm{Ca}_{\mathrm{V}}$ channels; recordings are performed upon repolarization to $-50 \mathrm{mV}$ (Hallworth et al., 2003; Stocker, 2004). Using digital subtraction (brown trace), essentially no apamin-sensitive current is isolated $(n=6)$. Ci, Representative $V_{\text {mem }}$ recording illustrating oscillatory activity before and after, as well as irregular discharge during wash-in of relatively low TEA concentrations (1 mm; horizontal bar indicates drug incubation). Cii, Ciii, Expanded view of periodic bursting before (Cii) and irregular activity during (Ciii) TEA treatment, respectively. Rhythmicity (as well as the lack thereof) is also evident from the corresponding $V_{\text {mem }}$ all-points histograms. Red arrowheads indicate $V_{\text {mem }}$ states $\left(V_{\mathrm{d}} ; V_{\mathrm{u}}\right)$ under synaptic isolation. Di, Using a prerecorded prototypical burst as the voltage-clamp command waveform (template; top), individual current components are isolated owing to their specific pharmacological profile. Currents sensitive to TEA (1 mM; middle) and $\mathrm{Cd}^{2+}$ (200 $\mu \mathrm{M}$; bottom) are obtained by successive digital subtraction. Red arrowheads indicate the first and a randomly chosen intermediate $\left(29^{\text {th }}\right)$ action potential (see below). Dii, Expanded view and overlay of TEA-sensitive and $\mathrm{Cd}^{2+}$-sensitive currents evoked by the first (light colors) and $29^{\text {th }}$ (dark colors) action potential, respectively. Note that, while the initial action potential shows the largest amplitude in the prerecorded burst template (Di), both peak current and charge transfer (trace integrals) evoked by the first spike are substantially smaller compared with later events. When TEA-sensitive (Diii) and $\mathrm{Cd}^{2+}$-sensitive (Div) charge transfer is normalized to each cell's maximum and plotted as a function of spike count (event number), the charge transfer function increased monotonically. Black dots represent results from individual measurements; red dots indicate means $[n=7$ (Diii) and 6 (Div)]. Curves were fit by monoexponential functions (red lines). Dv , Scatter plot depicting the relationship between TEA-sensitive and notion that BK channels play a major role in setting iAMC oscillation frequency.

\section{A "triangle" of interdependent distinct conductances is sufficient to drive autorhythmicity}

The above results indicate that mitral cell autorhythmicity emerges from coordinated reciprocal interaction of $I_{\mathrm{NaP}}, I_{\mathrm{R}}$, and $I_{\mathrm{BK}}$. While the molecular correlate of $I_{\mathrm{NaP}}$ is debated and subthreshold persistent currents might even originate from the same channels that carry suprathreshold transient currents (Carter et al., 2012), the $\mathrm{Ca}_{\mathrm{V}} 2.3$ channel and the $\mathrm{BK}$ channel $\alpha-1$ subunit $\operatorname{Slo} \alpha 1$ have been shown to mediate $I_{\mathrm{R}}$ and $I_{\mathrm{BK}}$, respectively. Indeed, antibodies raised against $\mathrm{Ca}_{\mathrm{V}} 2.3$ and Slo $\alpha 1$ label a large population of cells in the AOB mitral cell layer (Fig. 9A,B). Notably, the pharmacological profile of $I_{\mathrm{BK}}$ in AOB mitral cells-sensitivity to TEA and paxilline, but resistance to iberiotoxin and charybdotoxin (data not shown) suggests coexpression of an auxiliary $\beta 4$ subunit (Slo $\beta 4$ ) that confers type-II BK channel properties (Brenner et al., 2005), such as relatively slow gating kinetics. Immunolabeling against Slo $\beta 4$ confirmed its specific expression in $\mathrm{AOB}$ mitral cells (Fig. 9C). Moreover, both Slo $\alpha 1$ and Slo $\beta 4$ were expressed in neurons identified as iAMCs in prior electrophysiological recordings (Fig. 9D,E).

Are $I_{\mathrm{NaP}}, I_{\mathrm{R}}$, and $I_{\mathrm{BK}}$ unique properties of rhythmogenic AOB mitral cells or are these conductances broadly expressed in both iAMCs and nonrhythmogenic neurons? To address this question, we compared electrophysiological profiles of $I_{\mathrm{NaP}}$, $I_{\mathrm{R}}$, and $I_{\mathrm{BK}}$ in both mitral cell populations (Fig. 10A-G). All three currents are found in both iAMCs and irregularly firing mitral cells. However, with the exception of

\section{$\leftarrow$}

$\mathrm{Cd}^{2+}$-sensitive absolute charge transfer during a burst. Linear regression indicates strong correlation of both parameters (Pearson's correlation coefficient, $r=0.977 ; n=6$ ). Ei, Representative $V_{\text {mem }}$ recording of oscillatory discharge before (top) and during (bottom) paxilline treatment ( $5 \mu \mathrm{m}$; preincubation, $\geq 3 \mathrm{~min}$ ). Eii, Bar charts comparing iAMC discharge parameters $(n=8)$ under conditions of synaptic isolation (iso; black) versus additional inhibition of BK channels (paxilline; green). IBIs, burst durations, within-burst firing rates, and $V_{\text {mem }}$ states are plotted as means \pm SEM. Paxilline treatment shortened IBIs (13.9 \pm 2.0 vs $8.7 \pm 0.8 \mathrm{~s}$ ) and increased burst durations ( $5.5 \pm 1.1 \mathrm{vs} 10.6 \pm 1.9 \mathrm{~s})$. Firing frequencies $(3.4 \pm 0.6 \mathrm{vs} 3.9 \pm 0.5 \mathrm{~Hz})$ as well as $V_{\mathrm{d}}$ and $V_{\mathrm{u}}(-75.6 \pm 0.8$ vs $-75.1 \pm 1.4 \mathrm{mV} ;-65.2 \pm 0.9 \mathrm{vs}-62.0 \pm 1.1 \mathrm{mV})$ were essentially unaffected. Asterisks $\left({ }^{*}\right)$ denote statistical significance, $p<0.05$ (paired sample $t$ test). 
SNX-482-sensitive $I_{\mathrm{R}}$ (Fig. $10 D, E$ ), properties of rhythmogenic currents markedly differed between both neuronal populations. The $I_{\mathrm{NaP}}$ activation threshold was significantly lower in iAMCs than in nonrhythmogenic neurons (Fig. 10 A, Bi). In addition to the resulting left shift in the $I-V$ relationship (Fig. $10 C$ ), maximum $I_{\mathrm{NaP}}$ amplitudes-calculated from sigmoidal fits to the individual $I-V$ curveswere significantly increased in iAMCs (Fig. 10Bii). TEA-sensitive $\mathrm{K}^{+}$currents also differed between oscillating and irregularly firing mitral cells (Fig. $10 F, G$ ). Larger $I_{\mathrm{BK}}$ amplitudes are recorded from iAMCs and steady-state activation curves in oscillating neurons are considerably shifted toward lower $V_{\text {mem }}$ values (Fig. $10 G)$. These results show that, while not exclusively expressed in the intrinsically oscillating mitral cell population, $I_{\mathrm{NaP}}, I_{\mathrm{R}}$, and $I_{\mathrm{BK}}$ confer a distinct electrophysiological phenotype on iAMCs.

We next asked whether the interplay of $I_{\mathrm{NaP}}, I_{\mathrm{R}}$, and $I_{\mathrm{BK}}$ is sufficient to drive autorhythmicity in a model AOB mitral cell. Based on the volume-rendered 3D reconstruction of a representative iAMC (Fig. 10Hi), $V_{\text {mem }}$ simulations were run using the Neuron simulation environment (Hines and Carnevale, 1997). In addition to $I_{\mathrm{NaP}}, I_{\mathrm{R}}$, and $I_{\mathrm{BK}}$, the model neuron also expressed $I_{\mathrm{Kdr}}$ and $I_{\mathrm{KA}}$ (based on our own voltageclamp experiments; see Materials and Methods), as well as $I_{\mathrm{NaT}}$ (Migliore et al., 2005). Strikingly, model-based simulations qualitatively reproduced the experimental data, with relatively small changes in $\mathrm{K}_{\mathrm{dr}}$ channel density accounting for much of the experimentally observed heterogeneity in both IBIs and burst duration (Fig. 10Hii-Hiii). Together these data demonstrate that iAMCs express a "triangle" of conductances with distinct biophysical properties- $I_{\mathrm{NaP}}, \quad I_{\mathrm{R}}$, and $I_{\mathrm{BK}}$-that are sufficient to generate autorhythmicity in mouse AOB mitral cells.

\section{Discussion}

The accessory olfactory system is central to social information processing in various mammalian species. However, many basic physiological principles underlying sensory processing in the $\mathrm{AOB}$ remain poorly understood (Dulac and Wagner, 2006). Here, we investigate spontaneous activity in AOB mitral cells, the sole output/projection neurons of the AOB. We report that a group of AOB mitral cells displays slow stereotypical rhythmic discharge both in vitro and in vivo. Among these
A (i)

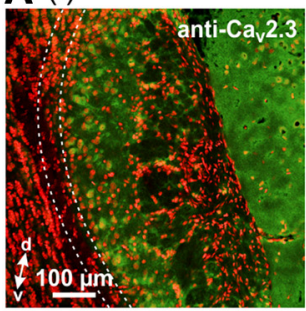

B (i)

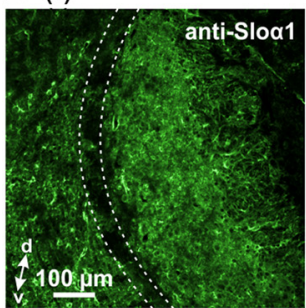

C (i)

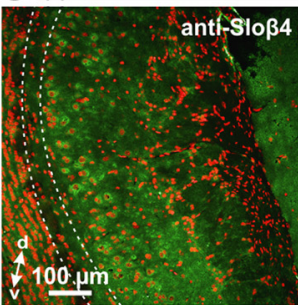

D (i)

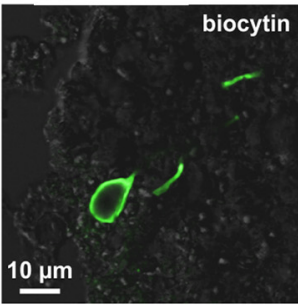

E (i)

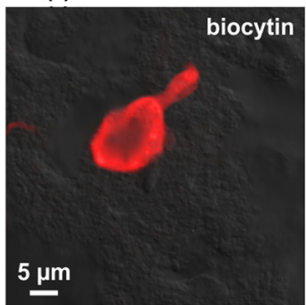

(ii)

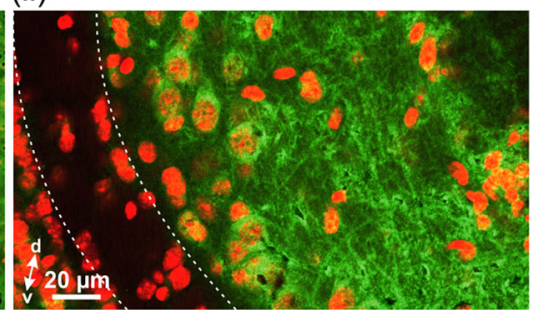

(ii)

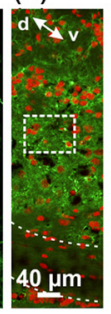

(ii)

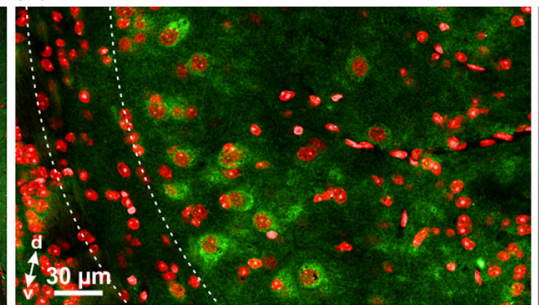

(ii)

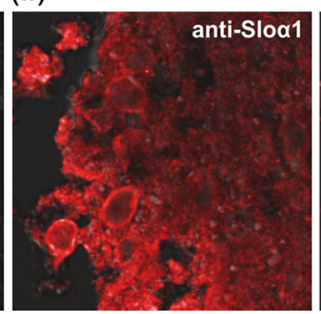

(ii)

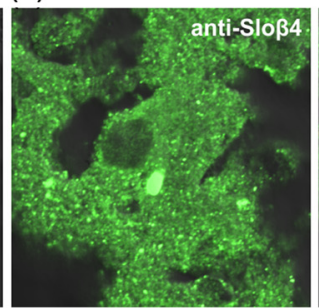

(iii)

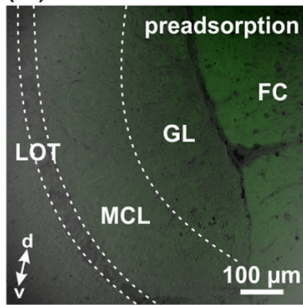

(iii)

(iii)

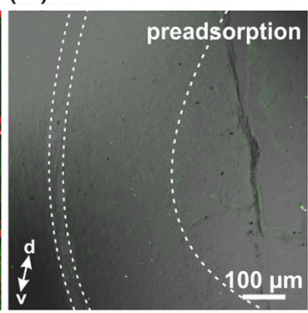

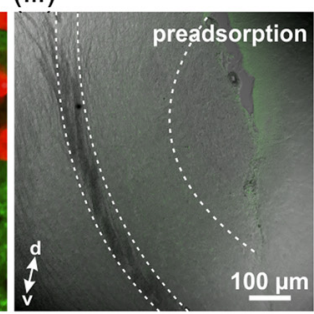

(iii)

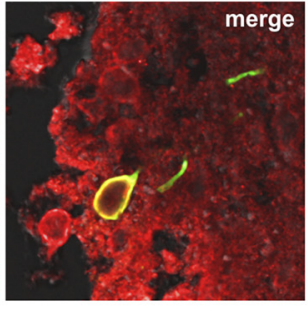

(iii)

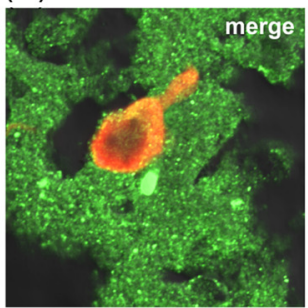

(iv)

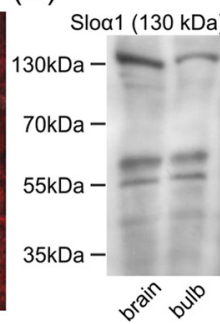

(iv)

Sloß4 $(22 \mathrm{kDa})$
$55 \mathrm{kDa}-$

$35 \mathrm{kDa}-$

$25 \mathrm{kDa}-$

$15 \mathrm{kDa}-\frac{}{0^{20}}$

Figure 9. Expression of $B K$ and $C_{\mathrm{v}} 2.3$ channels in $A O B$ mitral cells. $A-C$, Confocal laser-scanning microscopy images of the mouse AOB (parasagittal cryosections). Immunofluorescence labeling (green) of $\mathrm{Ca}_{\mathrm{v}} 2.3(\boldsymbol{A})$ ), the BK channel subunit $\alpha-1$ (Slo $\alpha 1$; $\boldsymbol{B})$, and the BK channel subunit $\beta-4$ (Slo $\beta 4 ; \boldsymbol{C}$ ). Nuclei are counterstained with DRAQ5 (red). Dashed lines indicate both the lateral olfactory tract (LOT) and the glomerular layer (GL) in Aiii, Biii, and Ciii. Representative single optical section images show an overview of the $A O B$ ( $\boldsymbol{A i}, \boldsymbol{B i}, \mathbf{C}$ ) and a high-magnification view (Aii, Bii, Cii) of the mitral cell layer (MCL). Note the robust labeling of cells in the MCL as well as the absence of immunofluorescence following peptide preadsorption (Aiii, Biii, Ciii; no DRAQ5 counterstaining). $\boldsymbol{D}, \boldsymbol{E}$, Post hoc immunolabeling of previously recorded intrinsically rhythmic neurons. Confocal images of $A O B$ cryosections containing biocytin-filled iAMC somata and proximal dendrites (visualized by Alexa Fluor 488/633 streptavidin conjugate). Sections were counterstained against the BK channel $\alpha-1(\boldsymbol{D})$ and $\beta-4(\boldsymbol{E})$ subunits, respectively. Merged images (Diii, Eiii) reveal BK expression in these representative iAMCs. Div, Eiv, Western blot analysis of total olfactory bulb (right lanes) and posterior brain (left lanes) protein extracts. Immunoblots were probed with anti-Slo $\alpha 1(\boldsymbol{D})$ and anti-Slo $\beta 4(\boldsymbol{E})$ antibodies, respectively. Expected band size is indicated above both blots. d, Dorsal; FC, frontal cortex; v, ventral.

neurons, a subpopulation is intrinsically rhythmogenic. In these pacemaker-like cells, reciprocal interactions between depolarizing and hyperpolarizing conductances generate stable patterns of $V_{\text {mem }}$ oscillations within a broad spectral window. 
A

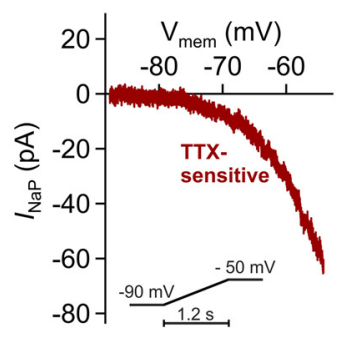

B (i)

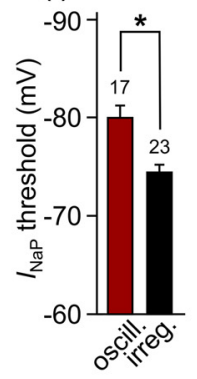

D

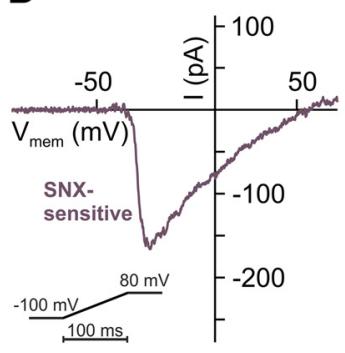

$\mathbf{F}$

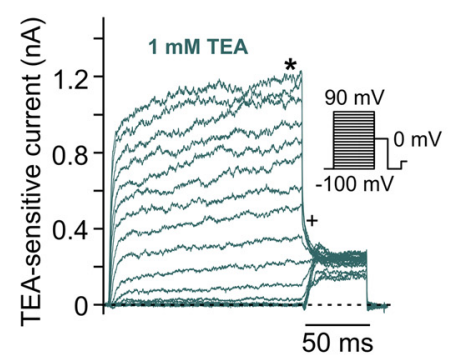

$\mathbf{H}$ (i)

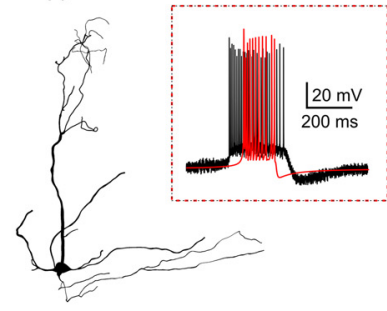

G

(ii)

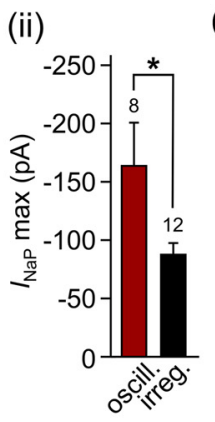

(ii)
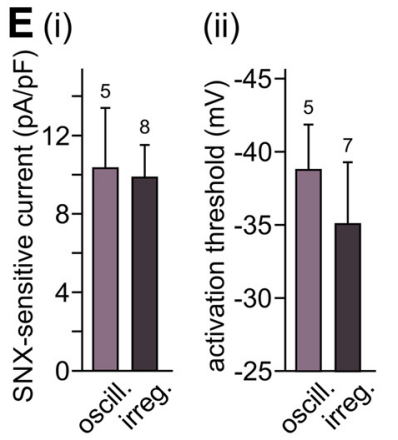

C

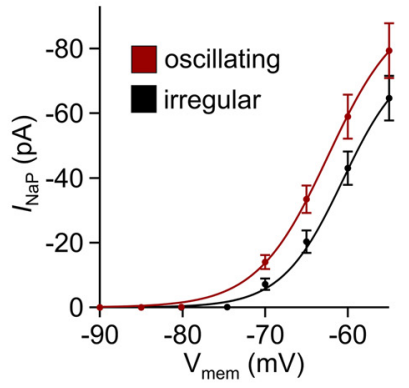

(iii) (iv)
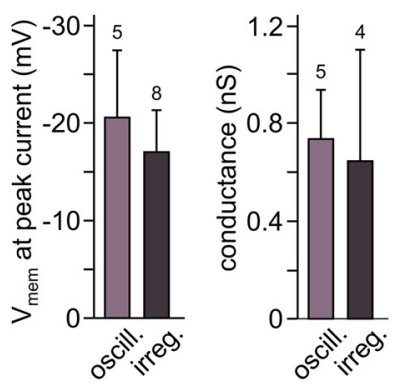

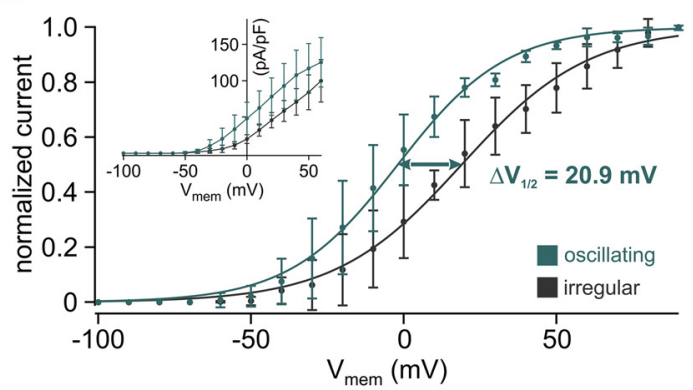

(iii)

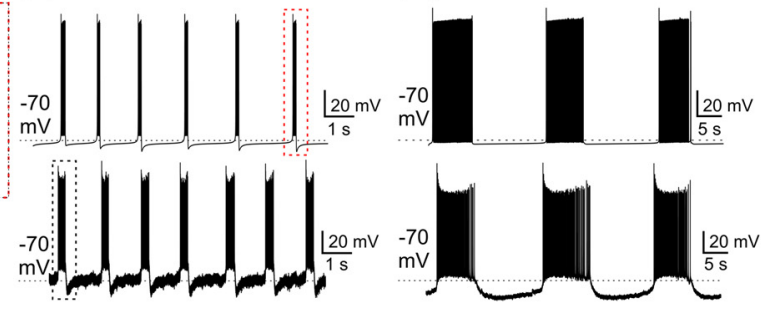

Figure 10. A distinct combination of currents is sufficient to generate iAMC autorhythmicity. $A, I-V$ relationship of TTXsensitive whole-cell currents ( $300 \mathrm{~nm}$; mean of 3 consecutive recordings; $I_{\mathrm{NaP}}$ isolated by digital subtraction) evoked by slow (10 $\mathrm{mV} / 300 \mathrm{~ms}$ ) ascending voltage ramps from -90 to $-50 \mathrm{mV}$ (inset) in a representative iAMC under synaptic isolation [gabazine $(10 \mu \mathrm{M})+\mathrm{AP5}(100 \mu \mathrm{M})+\mathrm{NBQX}(10 \mu \mathrm{m})] . \mathbf{B i}, \mathbf{B i i}$, Bar diagrams quantifying either $(\boldsymbol{B i})$ the average activation threshold of $/ \mathrm{NaP}$ in iAMCs (oscill.; red; $V_{\text {threshold }}=-80.1 \pm 1.2 \mathrm{mV}$ ) versus nonrhythmogenic neurons (irreg.; black; $V_{\text {threshold }}=-74.6 \pm 0.7 \mathrm{mV}$ ) or $\left(\right.$ Bii) the maximum $/_{\mathrm{NaP}}$ amplitude in oscillating (red; $-164.0 \pm 36.8 \mathrm{pA}$ ) versus irregular neurons (black; $\left.-87.9 \pm 9.7 \mathrm{pA}\right)$. Data are means \pm SEM. Asterisks $\left(^{*}\right)$ denote statistical significance, $p<0.0001$ (Bi) or $p<0.05$ (Bii; unpaired sample $t$ test) Numbers of experiments are denoted above bars. C, Average I-V relationships of TTX-sensitive $I_{\text {NaP }}$ recorded from oscillating (red; $n=6-17$ ) versus irregular mitral cells (black; $n=16-23$ ). Data points depict means \pm SEM. Curves are sigmoidal Boltzmanntype equation fits assuming threshold $V_{\text {mem }}$ values shown in $B i$. $V_{\text {mem }}$ values corresponding to half-maximal activation are -60.4 $\pm 0.8 \mathrm{mV}$ versus $-60.6 \pm 14.5 \mathrm{mV}$ in oscillating and irregular neurons, respectively. $D, S N X-482(100 \mathrm{~nm})$ sensitive $I_{R}$ recorded from an irregularly firing mitral cell under synaptic isolation in response to a fast ascending voltage ramp ( -100 to $+80 \mathrm{mV} ; 100$ ms duration) and plotted as a function of command voltage. $\boldsymbol{E}$, Bar charts comparing $I_{\mathrm{R}}$ characteristics in oscillating (violet) versus irregular (black) mitral cells. Ei-Eiv, SNX-sensitive peak current (Ei; $10.3 \pm 3.1 \mathrm{vs} 9.9 \pm 1.6 \mathrm{pA} / \mathrm{pF}$ ), activation threshold (Eii; $-38.8 \pm 3.1 \mathrm{vs}-35.1 \pm 4.2 \mathrm{mV}$ ), $V_{\text {mem }}$ inducing maximum currents (Eiii; $-20.6 \pm 6.9 \mathrm{vs}-17.1 \pm 4.3 \mathrm{mV}$ ), and R-type channel conductance (Eiv; $0.73 \pm 0.2$ vs $0.64 \pm 0.5 \mathrm{nS}$ ) are not significantly different between both mitral cell populations (unpaired sample $t$ test). Data are means \pm SEM. Numbers of experiments are denoted above bars. $\boldsymbol{F}, \mathrm{K}^{+}$current sensitive to TEA $\left(1 \mathrm{~mm}\right.$ ) recorded from a representative iAMC (whole-cell voltage clamp). Inset depicts pulse protocol. $\mathbf{G}$, Normalized $I_{\text {BK }}$ activation

The prevalence of slow oscillatory discharge was larger in $\mathrm{AOB}$ slices than observed in vivo. While we recorded rhythmic bursting in $16.7 \%$ of all units in vivo, $69.7 \%$ of $\mathrm{AOB}$ mitral cells displayed periodic discharge in vitro. Several factors could account for this apparent discrepancy. First, AOB slices are isolated from both peripheral sensory input and top-down modulation. When connectivity is intact, either factor could add substantial "noise" to a given mitral cell's output. Second, experimental in vitro conditions might favor oscillatory discharge. While we performed loose-seal extracellular recordings in parallel to whole-cell patchclamp measurements to prevent dialysis of intracellular components, extracellular in vitro conditions might not exactly mirror endogenous ionic concentrations. For example, our data indicate that small differences in $\left[\mathrm{Ca}^{2+}\right]_{\mathrm{ex}}$ could exert profound effects on rhythmogenesis. Regardless of the exact prevalence, slow/infraslow mitral cell rhythmicity will likely have considerable physiological impact on sensory processing along the accessory olfactory pathway.

At the lower end of the "bandwidth" scale (Buzsáki, 2006), infraslow oscillations with a periodicity of tens of seconds have been described in a variety of neurons and circuits (Hughes et al., 2002; Blethyn et al., 2006; Crunelli and Hughes, 2010; Buzsáki et al., 2013). In iAMCs, rhythmogenesis appears to be driven by cyclical interplay of $\geq 3$ voltagedependent and/or $\mathrm{Ca}^{2+}$-dependent conductances. Low threshold $I_{\mathrm{NaP}}$ functions as the major excitatory element that drives iAMC transition from $V_{\mathrm{d}}$ to $V_{\mathrm{u}}$. R-type $\mathrm{Ca}_{\mathrm{V}}$ channels play a significant role in oscillation maintenance and shape, while the resulting increase in cytoplasmic $\mathrm{Ca}^{2+}$ is coupled to progres-

curve recorded from oscillating (green, $n=3$ ) versus irregular (black, $n=3$ ) mitral cells. Steady-state current amplitudes are measured upon stepping back to $0 \mathrm{mV}(+$ in $\boldsymbol{F}$ ) and plotted as a function of prepulse $V_{\text {mem }}$. Solid lines represent sigmoidal fits to data points (mean $\pm S D ; V_{1 / 2}=-2.0 \pm 0.8$ vs $19.0 \pm$ $0.7 \mathrm{mV}) . V_{1 / 2}$ shift as indicated. Inset depicts average steadystate current densities of TEA-sensitive $I_{\mathrm{BK}}\left({ }^{*} \mathrm{in} F\right.$ ) as a function of command voltage ( $n=3$; means $\pm \mathrm{SD}$ ). Hi, Volumerendered $3 D$ reconstruction of a representative iAMC used for modeling spontaneous discharge. Hii, Hiii, Model-based $V_{\text {mem }}$ simulations (top) qualitatively reproduce experimental recordings (bottom) with respect to both IBIs and burst durations. Note that the different $V_{\text {mem }}$ simulation outcomes result mainly from model variation in $\mathrm{K}_{\mathrm{dr}}$ channel density and deactivation time constant. 
sive activation of BK channels which, in concert with slow voltage-dependent $I_{\mathrm{NaP}}$ inactivation (Jasinski et al., 2013), ultimately causes burst termination. Here, we observed that $I_{\mathrm{NaP}}$ becomes evident in iAMCs at voltages $\geq-80 \mathrm{mV}$. This finding supports recent reports of $I_{\mathrm{NaP}}$ activation at more negative voltages than previously appreciated (Huang and Trussell, 2008; Carter et al., 2012). The $I_{\mathrm{NaP}}$ pacemaking "engine" can therefore be engaged or disengaged by small shifts in net current at the down-state $V_{\text {mem }}$ range (Yamada-Hanff and Bean, 2013). In nonrhythmogenic neurons, the $I_{\mathrm{NaP}}$ activation threshold is shifted to $\sim-75 \mathrm{mV}$, a $V_{\text {mem }}$ value that is more positive than the down state in most iAMCs (median $V_{\mathrm{d}}=$ $-76.4 \mathrm{mV}$ ). An interplay of R-type $\mathrm{Ca}_{\mathrm{V}}$ and $\mathrm{BK}$ channels also supports relatively prolonged bursting. $I_{\mathrm{R}}$, which contributes to bursting in hippocampal (Metz et al., 2005) and thalamic reticular neurons (Zaman et al., 2011), is similar to $I_{\mathrm{T}}$ but activates above threshold (Foehring et al., 2000). Importantly, among high-voltage-activated $\mathrm{Ca}^{2+}$ channels, only R-type channels do not associate with $\mathrm{BK}$ channels in $\mathrm{Ca}^{2+}$ nanodomains (Fakler and Adelman, 2008), indicating the requirement of a slower, more global increase in cytoplasmic $\mathrm{Ca}^{2+}$ to activate substantial $I_{\mathrm{BK}}$. Together with the pronounced left shift in the $V_{\text {mem }}$ dependence of $I_{\mathrm{BK}}$ activation that we observed in iAMCs, the specific $I_{\mathrm{R}}-I_{\mathrm{BK}}$ combination expressed in oscillating neurons appears ideally suited to shape autorhythmicity.

Our results do not exclude a functional role of other conductances or electrogenic pumps (Krey et al., 2010; Zylbertal et al., 2015). While we could not demonstrate a significant contribution of $I_{\mathrm{h}}, I_{\mathrm{T}}$, or L-type, P-type/Q-type, and N-type $\mathrm{Ca}^{2+}$ currents or SK channel-mediated $\mathrm{K}^{+}$currents, the activity-dependent cytoplasmic build-up of $\mathrm{Na}^{+}$and/or $\mathrm{Ca}^{2+}$ during the burst could additionally "recruit" other currents. Potential candidates include $\mathrm{Na}^{+}$-activated $\mathrm{K}^{+}$currents (Hage and Salkoff, 2012) and $\mathrm{Ca}^{2+}$-activated nonselective cation currents (Peña et al., 2004; Blethyn et al., 2006; Shpak et al., 2012). The $\mathrm{Na}^{+}$-activated $\mathrm{K}^{+}$ current, in particular, could prove important by mitigating $I_{\mathrm{NaP}^{-}}$ dependent depolarization, effectively decelerating the $V_{\mathrm{d}}$-to- $V_{\mathrm{u}}$ transition. Indeed, the biophysical foundation of pacemaker-like activity (e.g., in central pattern generators) is often redundant, such that identical firing patterns can be achieved by multiple current combinations (Marder and Goaillard, 2006). Notwithstanding, when added to a model mitral cell that otherwise expresses "standard" Hodgkin-Huxley-type voltage-gated $\mathrm{Na}^{+}$ and $\mathrm{K}^{+}$channels, the combination of $I_{\mathrm{NaP}}, I_{\mathrm{R}}$, and $I_{\mathrm{BK}}$ is sufficient to drive autorhythmicity.

To what extent intrinsically rhythmogenic mitral cells shape information processing and sensory coding in the $\mathrm{AOB}$ remains so far unexplored. Future experiments will thus have to address the impact of iAMC oscillatory discharge on the intact AOB network. The wide spectrum of discharge patterns, as well as the absence of a dominant oscillation frequency among iAMCs, argues against a distinct prevalent AOB rhythm. Instead, parallel pacemaker-like activity of phenotypically different iAMCs might generate synchronous discharge in several $\mathrm{AOB}$ microcircuits. By temporally linking $\mathrm{AOB}$ neurons into functional assemblies, synchronous firing could facilitate synaptic plasticity and input selection (Buzsáki and Draguhn, 2004). Rhythmic cycles between high and low postsynaptic excitability states would add a temporal dimension to a given circuit's sensory coding space (Schroeder and Lakatos, 2009). Similar to intrinsic theta frequency oscillations that entrain to the sniffing cycle in ET cells of the MOB (Hayar et al., 2004, 2005), operation of the vomeronasal pump
(Meredith and O'Connell, 1979) could entrain iAMC oscillations. In the hamster vomeronasal organ, peristaltic vasoconstriction cycles of $0.2-0.5 \mathrm{~Hz}$ were recorded in vivo (Meredith, 1994). In addition to input entrainment, orchestration of AOB neurons into functional ensembles could ensure communication reliability and selectivity (Izhikevich et al., 2003) by controlling signal flow among anatomically connected networks. Notably, downstream processing modules for vomeronasal stimuli include several nuclei that mediate pulsatile neuroendocrine release by synchronized slow rhythmic bursting of, for example, gonadotropin-releasing hormone neurons (Chu et al., 2012) or vasopressin magnocellular neurosecretory cells (Brown, 2004).

In summary, we identify a subpopulation of $\mathrm{AOB}$ mitral cells that exhibit slow/infraslow spontaneous rhythmicity both in vivo and in vitro. Some of these projection neurons are intrinsically rhythmogenic. The mechanistic basis of mitral cell autorhythmicity is the coordinated interplay of a regenerative subthreshold $\mathrm{Na}^{+}$current, a high voltage-activated $\mathrm{R}$-type $\mathrm{Ca}^{2+}$ current, and a burst-terminating $\mathrm{Ca}^{2+}$-activated $\mathrm{K}^{+}$current that is cooperatively activated by depolarization and cytoplasmic $\mathrm{Ca}^{2+}$ accumulation.

\section{References}

Adams ME, Myers RA, Imperial JS, Olivera BM (1993) Toxityping rat brain calcium channels with omega-toxins from spider and cone snail venoms. Biochemistry 32:12566-12570. CrossRef Medline

Alger BE, Nicoll RA (1980) Epileptiform burst afterhyperolarization: calcium-dependent potassium potential in hippocampal CA1 pyramidal cells. Science 210:1122-1124. CrossRef Medline

Barry PH (1994) JPCalc, a software package for calculating liquid junction potential corrections in patch-clamp, intracellular, epithelial and bilayer measurements and for correcting junction potential measurements. J Neurosci Methods 51:107-116. CrossRef Medline

Bean BP (2007) The action potential in mammalian central neurons. Nat Rev Neurosci 8:451-465. Medline

Ben-Shaul Y, Katz LC, Mooney R, Dulac C (2010) In vivo vomeronasal stimulation reveals sensory encoding of conspecific and allospecific cues by the mouse accessory olfactory bulb. Proc Natl Acad Sci U S A 107: 5172-5177. CrossRef Medline

Blankenship AG, Feller MB (2010) Mechanisms underlying spontaneous patterned activity in developing neural circuits. Nat Rev Neurosci 11: 18-29. Medline

Blatz AL, Magleby KL (1986) Single apamin-blocked Ca-activated K+ channels of small conductance in cultured rat skeletal muscle. Nature 323:718-720. CrossRef Medline

Blethyn KL, Hughes SW, Tóth TI, Cope DW, Crunelli V (2006) Neuronal basis of the slow $(<1 \mathrm{~Hz})$ oscillation in neurons of the nucleus reticularis thalami in vitro. J Neurosci 26:2474-2486. CrossRef Medline

BoSmith RE, Briggs I, Sturgess NC (1993) Inhibitory actions of ZENECA ZD7288 on whole-cell hyperpolarization activated inward current (If) in guinea-pig dissociated sinoatrial node cells. Br J Pharmacol 110:343-349. CrossRef Medline

Bossert F, Vater W (1989) 1,4-Dihydropyridines-A basis for developing new drugs. Med Res Rev 9:291-324. CrossRef Medline

Bourinet E, Stotz SC, Spaetgens RL, Dayanithi G, Lemos J, Nargeot J, Zamponi GW (2001) Interaction of SNX482 with domains III and IV inhibits activation gating of alpha $(1 \mathrm{E})(\mathrm{Ca}(\mathrm{V}) 2.3)$ calcium channels. Biophys J 81:79-88. CrossRef Medline

Brenner R, Chen QH, Vilaythong A, Toney GM, Noebels JL, Aldrich RW (2005) BK channel b4 subunit reduces dentate gyrus excitability and protects against temporal lobe seizures. Nat Neurosci 8:1752-1759. CrossRef Medline

Brown CH (2004) Rhythmogenesis in vasopressin cells. J Neuroendocrinol 16:727-739. CrossRef Medline

Bucher D, Taylor AL, Marder E (2006) Central pattern generating neurons simultaneously express fast and slow rhythmic activities in the stomatogastric ganglion. J Neurophysiol 95:3617-3632. CrossRef Medline

Buzsáki G (2006) Rhythms of the brain. New York: Oxford UP. 
Buzsáki G, Draguhn A (2004) Neuronal oscillations in cortical networks. Science 304:1926-1929. CrossRef Medline

Buzsáki G, Logothetis N, Singer W (2013) Scaling brain size, keeping timing: evolutionary preservation of brain rhythms. Neuron 80:751-764. CrossRef Medline

Carter BC, Giessel AJ, Sabatini BL, Bean BP (2012) Transient sodium current at subthreshold voltages: activation by EPSP waveforms. Neuron 75:1081-1093. CrossRef Medline

Castro JB, Hovis KR, Urban NN (2007) Recurrent dendrodendritic inhibition of accessory olfactory bulb mitral cells requires activation of group I metabotropic glutamate receptors. J Neurosci 27:5664-5671. CrossRef Medline

Chan CS, Shigemoto R, Mercer JN, Surmeier DJ (2004) HCN2 and HCN1 channels govern the regularity of autonomous pacemaking and synaptic resetting in globus pallidus neurons. J Neurosci 24:9921-9932. CrossRef Medline

Chu Z, Tomaiuolo M, Bertram R, Moenter SM (2012) Two types of burst firing in gonadotrophin-releasing hormone neurones. J Neuroendocrinol 24:1065-1077. CrossRef Medline

Cichy A, Ackels T, Tsitoura C, Kahan A, Gronloh N, Söchtig M, Engelhardt CH, Ben-Shaul Y, Müller F, Spehr J, Spehr M (2015) Extracellular pH regulates excitability of vomeronasal sensory neurons. J Neurosci 35: 4025-4039. CrossRef Medline

Colwell CS (2011) Linking neural activity and molecular oscillations in the SCN. Nat Rev Neurosci 12:553-569. CrossRef Medline

Crill WE (1996) Persistent sodium current in mammalian central neurons. Annu Rev Physiol 58:349-362. CrossRef Medline

Crunelli V, Hughes SW (2010) The slow $(<1 \mathrm{~Hz})$ rhythm of non-REM sleep: a dialogue between three cardinal oscillators. Nat Neurosci 13: 9-17. CrossRef Medline

Crunelli V, Lörincz ML, Errington AC, Hughes SW (2012) Activity of cortical and thalamic neurons during the slow $(<1 \mathrm{~Hz})$ rhythm in the mouse in vivo. Pflugers Arch 463:73-88. CrossRef Medline

Del Punta K, Puche A, Adams NC, Rodriguez I, Mombaerts P (2002) A divergent pattern of sensory axonal projections is rendered convergent by second-order neurons in the accessory olfactory bulb. Neuron 35: 1057-1066. CrossRef Medline

Dulac C, Torello AT (2003) Molecular detection of pheromone signals in mammals: from genes to behaviour. Nat Rev Neurosci 4:551-562. CrossRef Medline

Dulac C, Wagner S (2006) Genetic analysis of brain circuits underlying pheromone signaling. Annu Rev Genet 40:449-467. CrossRef Medline

Fakler B, Adelman JP (2008) Control of $\mathrm{K}(\mathrm{Ca})$ channels by calcium nano/ microdomains. Neuron 59:873-881. CrossRef Medline

Foehring RC, Mermelstein PG, Song WJ, Ulrich S, Surmeier DJ (2000) Unique properties of R-type calcium currents in neocortical and neostriatal neurons. J Neurophysiol 84:2225-2236. Medline

Fukunaga I, Berning M, Kollo M, Schmaltz A, Schaefer AT (2012) Two distinct channels of olfactory bulb output. Neuron 75:320-329. CrossRef Medline

Gentet LJ, Stuart GJ, Clements JD (2000) Direct measurement of specific membrane capacitance in neurons. Biophys J 79:314-320. CrossRef Medline

Gleeson P, Steuber V, Silver RA (2007) neuroConstruct: a tool for modeling networks of neurons in 3D space. Neuron 54:219-235. CrossRef Medline

Grillner S (2006) Biological pattern generation: the cellular and computational logic of networks in motion. Neuron 52:751-766. CrossRef Medline

Gutierrez GJ, O’Leary T, Marder E (2013) Multiple mechanisms switch an electrically coupled, synaptically inhibited neuron between competing rhythmic oscillators. Neuron 77:845-858. CrossRef Medline

Hage TA, Salkoff L (2012) Sodium-activated potassium channels are functionally coupled to persistent sodium currents. J Neurosci 32:2714-2721. CrossRef Medline

Hallworth NE, Wilson CJ, Bevan MD (2003) Apamin-sensitive small conductance calcium-activated potassium channels, through their selective coupling to voltage-gated calcium channels, are critical determinants of the precision, pace, and pattern of action potential generation in rat subthalamic nucleus neurons in vitro. J Neurosci 23:7525-7542. Medline

Hammen GF, Turaga D, Holy TE, Meeks JP (2014) Functional organization of glomerular maps in the mouse accessory olfactory bulb. Nat Neurosci 17:953-961. CrossRef Medline
Harris KD, Henze DA, Csicsvari J, Hirase H, Buzsáki G (2000) Accuracy of tetrode spike separation as determined by simultaneous intracellular and extracellular measurements. J Neurophysiol 84:401-414. Medline

Hayar A, Karnup S, Shipley MT, Ennis M (2004) Olfactory bulb glomeruli: external tufted cells intrinsically burst at theta frequency and are entrained by patterned olfactory input. J Neurosci 24:1190-1199. CrossRef Medline

Hayar A, Shipley MT, Ennis M (2005) Olfactory bulb external tufted cells are synchronized by multiple intraglomerular mechanisms. J Neurosci 25:8197-8208. CrossRef Medline

Hazan L, Zugaro M, Buzsáki G (2006) Klusters, NeuroScope, NDManager: a free software suite for neurophysiological data processing and visualization. J Neurosci Methods 155:207-216. CrossRef Medline

Hille B (2001) Ion channels of excitable membranes, 3rd ed. Sunderland, MA: Sinauer Associates.

Hines ML, Carnevale NT (1997) The NEURON simulation environment. Neural Comput 9:1179-1209. CrossRef Medline

Hines ML, Carnevale NT (2001) NEURON: a tool for neuroscientists. Neurosci 7:123-135. Medline

Hovis KR, Ramnath R, Dahlen JE, Romanova AL, LaRocca G, Bier ME, Urban NN (2012) Activity regulates functional connectivity from the vomeronasal organ to the accessory olfactory bulb. J Neurosci 32:7907-7916. CrossRef Medline

Huang H, Trussell LO (2008) Control of presynaptic function by a persistent $\mathrm{Na}+$ current. Neuron 60:975-979. CrossRef Medline

Hughes SW, Cope DW, Blethyn KL, Crunelli V (2002) Cellular mechanisms of the slow $(<1 \mathrm{~Hz})$ oscillation in thalamocortical neurons in vitro. Neuron 33:947-958. CrossRef Medline

Izhikevich EM, Desai NS, Walcott EC, Hoppensteadt FC (2003) Bursts as a unit of neural information: selective communication via resonance. Trends Neurosci 26:161-167. CrossRef Medline

Jasinski PE, Molkov YI, Shevtsova NA, Smith JC, Rybak IA (2013) Sodium and calcium mechanisms of rhythmic bursting in excitatory neural networks of the pre-Bötzinger complex: a computational modelling study. Eur J Neurosci 37:212-230. CrossRef Medline

Kay LM, Beshel J, Brea J, Martin C, Rojas-Líbano D, Kopell N (2009) Olfactory oscillations: the what, how and what for. Trends Neurosci 32: 207-214. CrossRef Medline

Koizumi H, Smith JC (2008) Persistent Na+ and K+-dominated leak currents contribute to respiratory rhythm generation in the pre-Bötzinger complex in vitro. J Neurosci 28:1773-1785. CrossRef Medline

Krey RA, Goodreau AM, Arnold TB, Del Negro CA (2010) Outward currents contributing to inspiratory burst termination in preBötzinger complex neurons of neonatal mice studied in vitro. Front Neural Circuits 4:124. CrossRef Medline

Larriva-Sahd J (2008) The accessory olfactory bulb in the adult rat: a cytological study of its cell types, neuropil, neuronal modules, and interactions with the main olfactory system. J Comp Neurol 510:309-350. CrossRef Medline

LeDoux JE (2000) Emotion circuits in the brain. Annu Rev Neurosci 23: 155-184. CrossRef Medline

Leszkowicz E, Khan S, Ng S, Ved N, Swallow DL, Brennan PA (2012) Noradrenaline-induced enhancement of oscillatory local field potentials in the mouse accessory olfactory bulb does not depend on disinhibition of mitral cells. Eur J Neurosci 35:1433-1445. CrossRef Medline

Liu S, Shipley MT (2008) Multiple conductances cooperatively regulate spontaneous bursting in mouse olfactory bulb external tufted cells. J Neurosci 28:1625-1639. CrossRef Medline

Llinás R, Yarom Y (1986) Oscillatory properties of guinea-pig inferior olivary neurones and their pharmacological modulation: an in vitro study. J Physiol 376:163-182. CrossRef Medline

Luo M, Fee MS, Katz LC (2003) Encoding pheromonal signals in the accessory olfactory bulb of behaving mice. Science 299:1196-1201. CrossRef Medline

Ma J, Lowe G (2004) Action potential backpropagation and multiglomerular signaling in the rat vomeronasal system. J Neurosci 24:9341-9352. CrossRef Medline

Maccaferri G, McBain CJ (1996) The hyperpolarization-activated current (Ih) and its contribution to pacemaker activity in rat CA1 hippocampal stratum oriens-alveus interneurones. J Physiol 497:119-130. CrossRef Medline

Maex R, De Schutter E (1998) Synchronization of Golgi and granule cell 
firing in a detailed network model of the cerebellar granule cell layer. J Neurophysiol 80:2521-2537. Medline

Maier N, Tejero-Cantero A, Dorrn AL, Winterer J, Beed PS, Morris G, Kempter R, Poulet JF, Leibold C, Schmitz D (2011) Coherent phasic excitation during hippocampal ripples. Neuron 72:137-152. CrossRef Medline

Marder E, Goaillard JM (2006) Variability, compensation and homeostasis in neuron and network function. Nat Rev Neurosci 7:563-574. CrossRef Medline

Martin RL, Lee JH, Cribbs LL, Perez-Reyes E, Hanck DA (2000) Mibefradil block of cloned T-type calcium channels. J Pharmacol Exp Ther 295: 302-308. Medline

Marx M, Günter RH, Hucko W, Radnikow G, Feldmeyer D (2012) Improved biocytin labeling and neuronal 3D reconstruction. Nat Protoc 7:394-407. CrossRef Medline

McCleskey EW, Fox AP, Feldman DH, Cruz LJ, Olivera BM, Tsien RW, Yoshikami D (1987) Omega-conotoxin: direct and persistent blockade of specific types of calcium channels in neurons but not muscle. Proc Natl Acad Sci U S A 84:4327-4331. CrossRef Medline

Meredith M (1994) Chronic recording of vomeronasal pump activation in awake behaving hamsters. Physiol Behav 56:345-354. CrossRef Medline

Meredith M, O'Connell RJ (1979) Efferent control of stimulus access to the hamster vomeronasal organ. J Physiol 286:301-316. CrossRef Medline

Metz AE, Jarsky T, Martina M, Spruston N (2005) R-type calcium channels contribute to afterdepolarization and bursting in hippocampal CAl pyramidal neurons. J Neurosci 25:5763-5773. CrossRef Medline

Migliore M, Hines ML, Shepherd GM (2005) The role of distal dendritic gap junctions in synchronization of mitral cell axonal output. J Comput Neurosci 18:151-161. CrossRef Medline

Mizuseki K, Sirota A, Pastalkova E, Buzsáki G (2009) Theta oscillations provide temporal windows for local circuit computation in the entorhinalhippocampal loop. Neuron 64:267-280. CrossRef Medline

Moore GP, Perkel DH, Segundo JP (1966) Statistical analysis and functional interpretation of neuronal spike data. Annu Rev Physiol 28:493-522. CrossRef Medline

Peña F, Parkis MA, Tryba AK, Ramirez JM (2004) Differential contribution of pacemaker properties to the generation of respiratory rhythms during normoxia and hypoxia. Neuron 43:105-117. CrossRef Medline

Perez-Reyes E, Cribbs LL, Daud A, Lacerda AE, Barclay J, Williamson MP, Fox M, Rees M, Lee JH (1998) Molecular characterization of a neuronal low-voltage-activated T-type calcium channel. Nature 391:896-900. CrossRef Medline

Ramirez JM, Koch H, Garcia AJ 3rd, Doi A, Zanella S (2011) The role of spiking and bursting pacemakers in the neuronal control of breathing. J Biol Phys 37:241-261. CrossRef Medline

Richter JM, Schaefer M, Hill K (2014) Riluzole activates TRPC5 channels independently of PLC activity. Br J Pharmacol 171:158-170. CrossRef Medline

Rieke F, de Ruyter van Steveninck R, Bialek W (1997) Spikes: exploring the neural code (Sejnowski TJ, Poggio TA, eds). Cambridge, MA: MIT.

Romano SA, Pietri T, Pérez-Schuster V, Jouary A, Haudrechy M, Sumbre G (2015) Spontaneous neuronal network dynamics reveal circuit's functional adaptations for behavior. Neuron 85:1070-1085. CrossRef Medline

Schroeder CE, Lakatos P (2009) Low-frequency neuronal oscillations as in- struments of sensory selection. Trends Neurosci 32:9-18. CrossRef Medline

Shadlen MN, Newsome WT (1998) The variable discharge of cortical neurons: implications for connectivity, computation, and information coding. J Neurosci 18:3870-3896. Medline

Shao Z, Puche AC, Kiyokage E, Szabo G, Shipley MT (2009) Two GABAergic intraglomerular circuits differentially regulate tonic and phasic presynaptic inhibition of olfactory nerve terminals. J Neurophysiol 101: 1988-2001. CrossRef Medline

Shpak G, Zylbertal A, Yarom Y, Wagner S (2012) Calcium-activated sustained firing responses distinguish accessory from main olfactory bulb mitral cells. J Neurosci 32:6251-6262. CrossRef Medline

Simerly RB (2002) Wired for reproduction: organization and development of sexually dimorphic circuits in the mammalian forebrain. Annu Rev Neurosci 25:507-536. CrossRef Medline

Smear M, Shusterman R, O'Connor R, Bozza T, Rinberg D (2011) Perception of sniff phase in mouse olfaction. Nature 479:397-400. CrossRef Medline

Smith RS, Araneda RC (2010) Cholinergic modulation of neuronal excitability in the accessory olfactory bulb. J Neurophysiol 104:2963-2974. CrossRef Medline

Stocker M (2004) $\mathrm{Ca}(2+)$-activated $\mathrm{K}+$ channels: molecular determinants and function of the SK family. Nat Rev Neurosci 5:758-770. CrossRef Medline

Stowers L, Logan DW (2010) Sexual dimorphism in olfactory signaling. Curr Opin Neurobiol 20:770-775. CrossRef Medline

Su H, Alroy G, Kirson ED, Yaari Y (2001) Extracellular calcium modulates persistent sodium current-dependent burst-firing in hippocampal pyramidal neurons. J Neurosci 21:4173-4182. Medline

Sugai T, Miyazawa T, Yoshimura H, Onoda N (2005) Developmental changes in oscillatory and slow responses of the rat accessory olfactory bulb. Neuroscience 134:605-616. CrossRef Medline

Tazerart S, Vinay L, Brocard F (2008) The persistent sodium current generates pacemaker activities in the central pattern generator for locomotion and regulates the locomotor rhythm. J Neurosci 28:8577-8589. CrossRef Medline

Tolokh II, Fu X, Holy TE (2013) Reliable sex and strain discrimination in the mouse vomeronasal organ and accessory olfactory bulb. J Neurosci 33:13903-13913. CrossRef Medline

Veitinger S, Veitinger T, Cainarca S, Fluegge D, Engelhardt CH, Lohmer S, Hatt H, Corazza S, Spehr J, Neuhaus EM, Spehr M (2011) Purinergic signalling mobilizes mitochondrial $\mathrm{Ca}^{2+}$ in mouse Sertoli cells. J Physiol 589:5033-5055. CrossRef Medline

Wagner S, Gresser AL, Torello AT, Dulac C (2006) A multireceptor genetic approach uncovers an ordered integration of VNO sensory inputs in the accessory olfactory bulb. Neuron 50:697-709. CrossRef Medline

Yamada-Hanff J, Bean BP (2013) Persistent sodium current drives conditional pacemaking in CA1 pyramidal neurons under muscarinic stimulation. J Neurosci 33:15011-15021. CrossRef Medline

Zaman T, Lee K, Park C, Paydar A, Choi JH, Cheong E, Lee CJ, Shin HS (2011) Cav2.3 channels are critical for oscillatory burst discharges in the reticular thalamus and absence epilepsy. Neuron 70:95-108. CrossRef Medline

Zylbertal A, Kahan A, Ben-Shaul Y, Yarom Y, Wagner S (2015) Prolonged intracellular $\mathrm{Na}+$ dynamics govern electrical activity in accessory olfactory bulb mitral cells. PLoS Biol 13:e1002319. CrossRef Medline 